NBER WORKING PAPER SERIES

\title{
THE FUTURE OF OLD-AGE LONGEVITY: COMPETITIVE PRICING OF MORTALITY CONTINGENT CLAIMS
}

Charles Mullin

Tomas Philipson

Working Paper 6042

\author{
NATIONAL BUREAU OF ECONOMIC RESEARCH \\ 1050 Massachusetts Avenue \\ Cambridge, MA 02138 \\ May 1997
}

We thank the Society of Actuaries as well as Compulife for providing the data used. However, none of the conclusions discussed is attributable to these organizations. Seminar participants at The University of Chicago, the Aging \& Health Groups at NBER, Stockholm University, and Lund University also provided useful comments. We are particularly thankful for comments of Gary Becker, John Cawley, Lars Hansen, James Heckman, Joseph Hotz, Babak Koshnood, Ekaterini Kyriazidou, Anup Malani, Derek Neal, Joseph Newhouse, Edward Vytlacil, George Zanjani, and especially Casey Mulligan. David Grabowski and Diana Seger provided valuable research assistance. Philipson acknowledges support from NIA and The Faculty Research Fellow Program of the Alfred P. Sloan Foundation. This paper is part of NBER's research programs in Aging, Health Care and Health Economics. Any opinions expressed are those of the authors and not those of the National Bureau of Economic Research.

(C) 1997 by Charles Mullin and Tomas Philipson. All rights reserved. Short sections of text, not to exceed two paragraphs, may be quoted without explicit permission provided that full credit, including $\mathcal{C}$ notice, is given to the source. 
The Future of Old-Age Longevity: Competitive

Pricing of Mortality Contingent Claims

Charles Mullin and Tomas Philipson

NBER Working Paper No. 6042

May 1997

Aging, Health Care and Health Economics

\section{ABSTRACT}

The future course of old-age mortality is of great importance to public sector expenditures in countries where old-age programs, such as Social Security and Medicare in the US, account for large fractions of the public budget. This paper argues that the competitive market prices of mortality contingent claims, such as annuities and life insurance, contain information which allow one to infer the opinion of the market regarding the pace of the continued increase in old-age longevity. The paper develops methods to identify and estimate the mortality implicit in the market prices of such claims by identifying survival functions from prices of contracts that differ in their duration. Utilizing these methods, we provide estimates using cohort-specific prices of US term life insurance contracts in 1990-96 for individuals aged 60 in each calendar year. Our main finding is that the mortality patterns inferred from these prices indicate a continued decline in cohort-specific mortality at rates equal to or greater than recent historical trends; about a 5 percent reduction in relative terms in the mortality hazards per successive cohort.

Charles Mullin

Department of Economics

University of Chicago

1126 East 59th Street

Chicago, IL 60637
Tomas Philipson

Department of Economics

University of Chicago

1126 East 59th Street

Chicago, IL 60637

and NBER

t-philipson@uchicago.edu 


\section{Introduction}

Old-age longevity is central to public economies in most countries, especially in relation to health and social insurance expenditures on the elderly. In the US, spending on old-age programs, primarily Social Security and Medicare, grew from about a fifth to a third of total federal spending between 1965 and 1995. The number of countries that have old age or survivor income programs provided through the public sector has increased by almost five times since 1940 -from 33 to 155 . Although the financing of these programs varies widely across countries, the benefits are paid out almost exclusively in terms of annuities and they often cover more than 90 percent of the labor force. Indeed, public annuity programs are immense, both in terms of levels and growth: in OECD countries they constitute about one-tenth of GDP, make up more than three-quarters of all social insurance, and have contributed to a quarter of the growth in total public expenditures since $1960 .^{2}$

The yearly expenditures on such old-age programs are the product of two factors: the number of eligible individuals, which is set by age criteria, and the yearly per-capita expenditure of the program. Since the former is determined by the end tail of the age distribution and the programs are so large, small mortality effects may have large impacts on public expenditures. As a result of this fact, forecasting future longevity of old-age populations makes up a key component in future public spending projections. ${ }^{3}$ This concern for forecasting is strengthened by the recent increases in life expectancy as illustrated by the patterns in Figure 1 below.

The figure shows life expectancy conditional on reaching age 60 for males and females in six OECD countries over the period 1960 to $1995 .{ }^{4}$ The variance in the growth of longevity across countries is remarkable. For example,

\footnotetext{
${ }^{2}$ See, e.g., Older Workers, Retirement, and Pensions (1995), U.S. Department of Commerce, Economics and Statistics Administration, Bureau of the Census, and LifeSustaining Technologies and the Elderly (1987), Office of Technology Assessment, Congress of the United States, Washington, D.C.

${ }^{3}$ Forecasts of fertility also affect the upper tail of the age distribution, but for programs with a minimum age requirement, such as 65 years old for Social Security in the US, fertility is known for short term forecasts.

${ }^{4}$ These are cross sectional life-expectaricies, that is, current 60 year olds are assumed to die in the future according to how the cross-section of individuals older than them died in
} 
many eastern European countries, illustrated by Hungary, have experienced little growth in longevity, while others, such as Japan, have achieved remarkable growth at a rate of about two months per cohort. Most European countries and the US have experienced a slower growth, closer to one month per cohort. Given this steady growth in longevity, perhaps the central question of research on aging has become: Will this increase in longevity continue to grow at its current rate, and if not, at what rate?

To address such questions and their impact on public sector expenditures, demographers and public agencies have long forecast mortality. There is currently a large amount of literature on, and great disagreement concerning, whether future mortality decline will be at smaller or larger rates than recent historical trends. Indeed, forecasts have shown great variation across researchers and public institutions. This variance in results is interesting given that all groups work with the same mortality data. For example, the range of the U.S. Census projections of the number of Americans aged 85 and over in the year 2080 is between 9.8 and 33.9 million with estimates from the National Institute of Aging ranging up to 72 million.

This paper uses market prices to investigate what the implicit opinion about US old-age longevity is of sellers of mortality contingent claims, such as annuities and life-insurance. An important aspect of using market data is that the livelihood of the participants is directly tied to the accuracy of the longevity beliefs. For example, in life-insurance markets, inaccuracy either leads to insolvency when mortality is underestimated or being priced out of the market by better competitors when mortality is over-estimated. In essence, market prices implicitly reveal the disciplined expectations of the market about the future level of mortality when severe consequences are paid for being wrong. ${ }^{5}$ This paper discusses how to identify and estimate cohort

the most recent year. The countries selected (Australia, France, Hungary, Japan, Sweden, and The United States) were those with mortality data for the entire period from the source OECD Health Data 1996, OECD, Paris.

${ }^{5}$ There may be large incentives for biased estimates when one does not bear the consequences of being wrong. For example, government officials may have an incentive to greatly over-predict mortality since that results in government deficits looking smaller and pay-as-you-go trust funds appearing more solvent. Indeed, this perverse incentive is one interpretation of why the Office of Actuary in the US has consistently over-predicted mortality (Olshansky (1988) documents the methods used and results obtained by the US Office of the Actuary of The Social Security Administration.). Furthermore, academics are often tied to a particular school of thought or may have a professional incentive to deliver 
specific mortality. Using term-life insurance prices, we find that prices across time support the hypothesis of a continued reduction in mortality mimicking or increasing the recent historical decline.

The basic idea of this paper is to identify the implicit opinion of the market regarding future mortality by imposing zero profit conditions on the contracts marketed by life-product companies. To illustrate, by assuming zero profits by the issuer of the contract, the premium on a one year term life insurance contract can identify the one year mortality hazard of the individual purchasing the contract. Similarly, a two-year term life insurance contract contains information about the mortality experience up to two years. So, when observed together, one and two year contracts enable one to identify the expected mortality experience of both years. Treating these zero profit conditions as moment restrictions in a GMM framework, the entire survival function could be identified non-parametrically by successively longer contract durations. In other words, the price variation across contracts of different duration identifies the survival of the population insured. Although we restrict our attention to term life insurance contracts in our empirical analysis, the same ideas are applicable to any mortality contingent claims.

Our paper relates to substantial demographic and economic literature on the consequences of the observed decline in old-age mortality rates. ${ }^{6}$ Most of the differences in the literature's assessments of future declines in mortality boil down to different beliefs on the future course of mortality reducing behavior (e.g. smoking or diets), improvements in mortality reducing medical technology, and the importance of biological limits in mortality reduction. ${ }^{7}$ Since there is so much uncertainty about such determinants, incentives, rather than data, seem to be important in deciding what factors should be considered to be of central importance. ${ }^{8}$

predictions that are either extreme, different from the forecasts of others, or consistent with past predictions. (Philipson and Posner (1993) discuss the enormous over-predictions made by demographers regarding the prevalence of AIDS in the US and elsewhere in the world.)

${ }^{6}$ See Clark et al (1978), World Bank (1984), Manton and Stallard (1984), Manton et al (1996), Fogel (1994), Aaron et al (1989), Congressional Budget Office (1993), Rosenzweigh and Stark (1995), Skinner (1985,1991), Skinner and Lee (1996), Lee et al (1994), and Posner (1995) or the references contained therein.

${ }^{7}$ See Lee et al (1994), Manton and Singer (1994), Vaupel (1986).

${ }^{8}$ Indeed, much debate even exists in the academic community, although not in the life- 
The paper may be briefly outlined as follows: Section 2 discusses the general problem of using mortality contingent claims, such as annuities, lifeinsurance or reinsurance, to estimate survival functions. Then, we show how to generally interpret zero profit conditions across contracts as moment conditions in the context of a generalized method of moments (GMM) estimator. Section 3 applies the results to term life insurance contracts. Section 4 discusses how to use multiple contracts to set-identify, as opposed to pointidentify, survival parameters under weaker assumptions on the costs of the production of insurance. Section 5 provides our empirical analysis using the pricing software of the US term-life market during the years 1990-96. This section contains our main substantive finding; the decline in cohort specific mortality present in these prices indicates that it will continue at or above recent historical rates of decline. Indeed we find that hazard rates fall by about 5 percent in relative terms per cohort. Finally, Section 6 concludes.

\section{The General Problem of Inferring Mortal- ity from Contract Data}

In this section, we discuss the general identification and estimation problem using firm-specific data across different types of insurance contracts. This is easiest to describe in terms of the GMM-approach which utilizes contract specific zero profit restrictions as moment conditions. In the next section we apply this approach to term life-insurance markets.

Let the population mortality be characterized by a parameterized survival function $S(t \mid \theta)$ interpreted as the fraction of the population alive at age $t$ where $\theta$ is a vector of size $J$ of unknown parameters affecting the survival function. Note that knowledge of the survival function is equivalent to knowing the frequency of lifetimes $f(t \mid \theta)$ or the hazard function, $h(t \mid \theta) \equiv f(t \mid \theta) / S(t \mid \theta)$, defined as the fraction of the population alive at the end of age $t-1$ that die at age $t$. We are interested in uncovering $\theta$ from market prices for mortality contingent claims. There are many different versions of such claims, such as single and double life products, finite or open-ended duration products or products that differ in the investment structure of pre-

insurance industry, over the quantitative relevance of extrapolating to human mortality the observed experiences in non-human populations, such as insects and flies. 
mia. Furthermore, prices may come from different types of markets, most importantly direct markets for the claim, but also from re-insurance markets on larger bundles of claims. Here we discuss a general approach that is applicable to all types of life products and markets and, indeed, any insurance market, not only those insuring mortality. Throughout the paper, we assume that insurers act as if they are risk neutral. This assumption is motivated by the following two points: (1) The law of large numbers makes the survival of insured customers have approximately zero variance. (2) Insurance companies are traded on the stock market and, hence, each shareholder has a sufficiently small fraction of their wealth in any given company such that they behave in a risk neutral manner. Risk neutral behavior coupled with competition among producers implies that contracts are priced such that the present value of profits is zero. Note that costs of production may include non-claim related expenditures or so called loadings.

Let $k=1,2, . ., K$ index the types of contracts analyzed, such as all durations and award sizes considered for term insurance. Let $X$ be a $(H \times 1)$ random vector of observable contract variables such as price, award size, and duration of contracts, or any other features of the contract that can be observed. The general problem is how to use firm-specific data across the contracts, to estimate the parameters in $\theta$. Let $\Pi_{k}(x, \theta)$ be a random variable representing the profits on contract $k$ given the observable contract variables $x$ and the survival parameters $\theta$. Let $\theta_{o}$ denote the true value of the survival parameters and suppose that it satisfies the set of zero expected profit (moment) conditions

$$
E\left[\Pi_{k}\left(X, \theta_{o}\right)\right]=0, \quad k=1,2, . ., K
$$

where the expectation is taken over all firms having that contract. Each contract is assumed to have a given set of firms trading it. The data we analyze is then a random sample of $\left(n_{1}, n_{2}, . ., n_{K}\right)$ observations across each of the contracts where for each firm and contract we observe $x$. The vector of sample means of the profits across the contracts is

$$
\Pi(\theta) \equiv\left[\left(1 / n_{1}\right) \sum_{i=1}^{n_{1}} \Pi_{1}\left(x_{i}, \theta\right), \ldots \ldots . .,\left(1 / n_{K}\right) \sum_{i=1}^{n_{K}} \Pi_{K}\left(x_{i}, \theta\right)\right]
$$

The general methods of moments (GMM) estimate of the survival parameters is the value of $\theta$ that minimizes

$$
\Psi(\theta) \equiv \Pi^{T}(\theta) W \Pi(\theta)
$$


where $W$ is a $(K \times K)$ weighting matrix. Intuitively, the estimator is that survival that comes closest to making firms earn zero profits across all contracts. Under fairly general regularity conditions, the estimator $\hat{\theta}$ that minimizes this function is a consistent estimator of $\theta_{o}$ (see Hansen (1982)). The covariance matrix for the estimator is

$$
\operatorname{Var}(\hat{\theta})=\left[D^{T} W^{-1}(\hat{\theta}) D\right]^{-1}
$$

where $D$ is a $J \times K$ matrix representing the derivative of $\Pi(\theta)$ with respect to the vector $\theta$ and the weighting matrix is given by

$$
W(\hat{\theta})=\left(\begin{array}{cccc}
s_{1} / n_{1} & 0 & \ldots & 0 \\
0 & s_{2} / n_{1} & \ldots & 0 \\
\vdots & \vdots & \ddots & \vdots \\
0 & 0 & \ldots & s_{K} / n_{K}
\end{array}\right)
$$

where $s_{k}$ is the sample variance of profits for a given contract

$$
s_{k}=\frac{1}{n_{k}} \sum_{i=1}^{n_{k}} \Pi_{k}^{2}\left(x_{i}, \hat{\theta}\right)-\left[\frac{1}{n_{k}} \sum_{i=1}^{n_{k}} \Pi_{k}\left(x_{i}, \hat{\theta}\right)\right]^{2}
$$

It is important to note that the diagonal weighting matrix assumes that observations are independent across contracts which therefore abstracts from the same firms trading several contracts.

\section{Identification of Mortality through Term Life Insurance Prices}

Our empirical analysis uses term-life insurance contracts to estimate survival parameters using the general approcah spelled out above. Our data contains firm specific data on the following contract parameters: premium $(p)$, award size $(z)$, contract duration $(\tau)$, and mortality determinants sucl as age, gender, smoking status, and so called preferred health status. Additionally, the term structure of interest rates is known. Let $R(t)$ denote the present value of a dollar paid $t$ periods in the future. We will estimate a different set of survival parameters $\theta$ for each combination of cohort, gender, smoking status and preferred status. In doing so, we will utilize $K=24$ different types of contracts for each sub-population and, hence, equally many mornent conditions. 


\subsection{One Year Term Life Insurance}

To illustrate the ideas, we start with one year term insurance contracts in which an award $z$ is paid in case of death at the end of one year. In this spot market, the mortality of the policy identified is the one year hazard rate, $h(1)$, conditional on entering the contract. The profits, without loadings, are given by the excess of premia over the expected present value of the awards paid out

$$
\Pi(x, \theta)=p-h(1) R(1) z
$$

where the survival parameter of interest here is the one-year hazard $\theta=h(1)$ and the observable contract parameter that varies across firms is price $x=p$. Each contract defines a zero profit condition across firms of the form

$$
E[\Pi(X, \theta)]=E[p-h(1) R(1) z\}=0
$$

If different contracts $k=1,2, . . K$ are associated with different award sizes $z$ then there are as many of these moment conditions as the number of award sizes considered. To introduce production costs, beyond claim expenditures, denote $C$ the cost of production. The profits netting out this costs are then

$$
\Pi(\theta, x)=p-h(1) R(1) z-C
$$

with the corresponding moment conditions involving zero profits taking the form:

$$
E[\Pi(X, \theta)=E[p-h(1) R(1) z]-E[C]=0
$$

Thus there is an additional parameter to be estimated by the GMM estimator corresponding to the unknown mean cost of production. If again the types of contracts considered are associated with different award sizes, the mean production costs must be assume to be constant across contract types.

\subsection{Multiple Year Term Life Insurance}

Whenever the mortality contingent claims are long-term contracts rather than single year contracts, prices contain information about future mortality during the contract period. In particular, current prices for contracts of different length can be used to identify the future survival of a cohort. Consider term insurance for a duration of $\tau$ periods which has a premium of $p_{r}$ due 
at the beginning of each year and pays $z_{\tau}$ in case of death at the end of the year in which the death occurred. In this case the profits generalize from the case of one year contracts to

$$
\Pi(x, \theta)=p\left[\sum_{t=0}^{\tau-1} S(t \mid \theta) R(t)\right]-z\left[\sum_{t=1}^{\tau}[S(t-1 \mid \theta)-S(t \mid \theta)] R(t)\right]-C_{z}
$$

The first term is the present value of premia payments from survivors, a fraction $S(t \mid \theta)$ pays the per period price $p$ each period. The second term is the present value of claim expenditures paid to those that die each year, made up of the difference in the survival times the discounted value of the award size. The third and final term is the cost of production that is allowed to be specific to the size of the award of the contract. ${ }^{9}$

The $K$ contracts we use for a given survival function differ by award size and contract durations. Thus, there is a separate moment condition for each combination of the pair $(\tau, z)$ that a contract involves. Otherwise, GMM estimation is analogous to the one year contract case. However, it is important to realize that only the variation in term length can be used to identify the survival function. Furthermore, costs of production are allowed to vary with the award size, but not with the duration of the contract. ${ }^{10}$ If one allowed the costs of production to vary with both the award size and the duration of the contract, the survival function would not be identified. From the moment conditions of these types of contracts it becomes apparent that a contract of length $\tau$ can inform the analyst only about the survival in the years from period 1 through period $\tau$. Therefore, in order to nonparametrically identify the survival function for the first $\tau_{o}$ years, one would need data on contracts with durations of $\tau=1,2, . ., \tau_{o}$ years. In our data, the contracts are for durations of one, five, ten, fifteen and twenty years because these are the most liquid durations of term contracts traded. Thus, we can only identify and estimate a parametric survival function with the number of parameters less than the set of years in the support of the survival. We

\footnotetext{
${ }^{9}$ It is common for larger production costs in terms of underwiting to be undertaken for larger awards.

${ }^{10}$ Our assumption of common survival across contract durations, that $\theta$ does not depend on $\tau$, assumes that populations are not excluded from contracting dependent on the length of the contract. For example, if the company is willing to sell a five year term, it is willing to sell a ten year term to the same individual.
} 
consider a version of the Gomphertz survival function which has the wellknown feature of increasing hazard rates at increasing rates that are often present in old-age mortality data. The Gomphertz survival function takes the following form:

$$
S(t \mid \theta)=e^{\theta_{1}\left[1-e^{\theta_{2} t}\right]}
$$

so that, loosely speaking, the parameter $\theta_{1}$ affects the intercept and the parameter $\theta_{2}$ affects the slope of the hazard function. ${ }^{11}$

\section{Set-Identification using Multiple Contracts}

The previous discussion relied on point identification of survival functions through zero profit conditions. One argument against this technique is that the costs of production may be misspecified and, hence, the moment conditions may be misspecified. Therefore, this section asks what can be identified by solely imposing the weaker condition that prices must cover awards due to mortality. This is a weaker assumption because it only requires that the firms do not lose money after setting their costs of production to zero. We show that by using multiple contracts on the insured population, relying on both annuities and life-insurance, mortality may be set identified. The basic idea behind these bounds is that whenever one contract has claims paid contingent on living, and another on dying, both may be used to bound mortality under weaker assumptions on the costs of insurance production. In particular, given that an individual has entered a contract, higher mortality entails lower profits for life-insurers but higher profits for annuity-insurers.

An annuity is assumed to have an initial price denoted $P_{\tau}$ which pays for a benefit $Z_{\tau}$ for $\tau$ years which may possibly be indefinite. Under constant discounting, the zero profit condition for such an annuity is

$$
E\left[P_{\tau}-C_{\tau}-Z_{\tau}\left[\sum_{t=1}^{\tau} S(t \mid \theta) R^{t}\right]\right]=0
$$

\footnotetext{
${ }^{11}$ There are two specification tests of these moment conditions: First, one can perform standard tests of the over-identifying restrictions. Second, whenever hazard rates rise with age the duration interaction on the effects of awards on price is positive $\frac{d h}{d t} \geq 0 \Rightarrow \frac{d^{2} p}{d r d z} \geq 0$. Regressing prices on awards and durations and testing for this positive interaction allows for a simple specification test of zero profits and rising hazards.
} 
which says that the price is made up of non-claim related costs plus awards of present value $Z_{\tau} R(t)$ paid to the survivors of size $S(t \mid \theta)$ throughout the contract. Using different award sizes and durations, proceeding in a similar manner to life-insurance, the parameters may be identified and estimated. However, our concern is with how to bound the survival parameters under the following weaker assumptions: (1) The cost of production outside of paying the mortality contingent claims is non-negative. (2) Profits must be nonnegative when production costs outside of paying the mortality contingent claims are set equal to zero. Imposing the above two conditions on term life-insurance contracts implies that on average premia revenues must cover claims,

$$
p_{\tau}\left[\sum_{t=0}^{\tau} S(t \mid \theta) R^{t}\right] \geq z_{\tau}\left[\sum_{t=1}^{\tau} f(t \mid \theta) R^{t}\right]
$$

One can rewrite the discounted frequency in the left hand side of the above equation as a linear function of the discounted survival, as in

$$
\sum_{t=0}^{\tau} f(t \mid \theta) R^{t}=1+(R-1)\left[\sum_{t=0}^{\tau} S(t \mid \theta) R^{t}\right]
$$

Substituting this linear relationship into the inequality for the life-insurance contract we have

$$
p_{\tau}\left[\sum_{t=0}^{\tau} S(t \mid \theta) R^{t}\right] \geq z_{\tau}\left[1+(R-1) \sum_{t=1}^{\tau} S(t \mid \theta) R^{t}\right]
$$

which yields the following lower bound on the unit price of an annuity:

$$
\frac{1}{1-R+p_{\tau} / z_{\tau}} \leq \sum_{t=0}^{\tau} S(t \mid \theta) R^{t}
$$

Imposing our two conditions on an annuity of length $\tau$ requires the price of the annuity to be at least as great as the expected discounted sum of payments,

$$
P_{\tau} \geq Z_{\tau}\left[\sum_{t=0}^{\tau} S(t \mid \theta) R^{t}\right]
$$

Thus, the unit price of the annuity provides an upper bound on the claim related expenditures of such an annuity:

$$
\sum_{t=0}^{\tau} S(t \mid \theta) R^{t} \leq \frac{P_{\tau}}{Z_{\tau}}
$$


Since the two contracts provide an upper and lower bound, the parameters $\theta$ are set-identified. For example, in the case of no discounting this says that for all possible cost structures life-expectancy can be identified through the set

$$
E[T \mid \theta]=\sum_{t=0}^{\tau} S(t \mid \theta) \in\left[\frac{z}{p}, \frac{P}{Z}\right]
$$

In general, similar bounds can be made for all mortality contingent claims that pay awards either as a function of survivors or as a function of those not surviving. The above assumptions lead to an ambiguous direction on the bias term for contracts that pay awards both in states of survival and in states of death. Thus, to obtain the tightest bounds on mortality under the above assumptions, take as the lower bound the maximum of all the lower bounds available and take as the upper bound the minimum of all the upper bounds available.

\section{Empirical Analysis}

This section describes the market which we sample, the data set utilized, and our price estimates of the mortality obtained from these data.

\subsection{Term Life Insurance and Mortality Related Regu- lation}

Life insurance constitutes one of the major forms of insurance in the US and many other developed countries. In 1992, $78 \%$ of U.S. households owned life insurance, for a total of $\$ 11,105$ billion in awards. ${ }^{12}$ About $71 \%$ of adult men and $64 \%$ of adult women in the U.S. have life insurance and men hold twice as much insurance as women, on average $\$ 105,500$ for men and $\$ 52,700$ for women. ${ }^{13}$ US life insurance contracts can be classified into several categories, one of which is term life insurance. Term insurance lasts for a specific period of time and payment of the award occurs only if the insured individual dies within the term of the contract. This type of insurance represents $22 \%$ of

\footnotetext{
${ }^{12}$ American Council of Life Insurance, Life Insurance Fact Book 1994, p. 6.

${ }^{13} \mathrm{Tbid}$, p. 34.
} 
the life insurance market. ${ }^{14}$

There are a few regulatory issues for term insurance that should be noted when inferring mortality from prices. The life-insurance industry in the US is regulated mainly through state agencies coordinated federally through the National Association of Insurance Commissioners (NAIC). The intended purpose of the regulation is to prevent insolvencies. As such, its main concern is the asset holdings of insurers, both in terms of quantity (reserves) and risk exposure (types of investments allowed). The important point is that premia are not directly regulated. The gist of the regulation requires insurers to keep reserves high enough to enable them to cover outlays according to a set of mortality tables compiled through the mortality experience of the industry. These tables are called CSO (Commissioners Standard Ordinary) tables and versions of these tables are produced about every 20 years, the latest in $1980 .{ }^{15}$ Given the decline in mortality over time, these tables are outdated for most of the 20 year period they are intended to cover. Therefore, competition forces prices much below what would be needed to cover the mortality of the most recent CSO table. So, insurers must adopt whatever mortality expectations they believe are sustainable using the two forms of data available to them: their own claims data and the mortality data in the public domain. ${ }^{16}$

\footnotetext{
${ }^{14} \mathrm{Ibid}$, p. 20,34 . Term insurance represents $38 \%$ of ordinary life insurance, which in turn represents $58 \%$ of the market.

${ }^{15}$ The next table is planned in 2000. For the 1980 CSO Table see Transactions of Society of Actuaries, v 33, 1981, p 617-34. For mortality statistics of the industry since then see Transactions of Society of Actuaries: Reports, 1991/92, p 3-40 for 1987-88 and Transactions of Society of Actuaries: Reports, 1995/96, (forthcoming) for 1988-90. These tables come in two versions; one with margins added for extra reserve requirements and one with the unaltered mortality data.

${ }^{16}$ Interestingly, some insurers argue that they get mortality information through their reinsurance prices; the argument made here for these primary insurers. Reinsurance prices reflect the mortality of the larger pool of contracts that the re-insurer faces. These data are viewed as one of the purest measures of mortality for an insured population because costs of production in re-insurance is much smaller than in insurance. We were unable to obtain re-insurance data but if such data are available it may be preferred to primary insurance data.
} 


\subsection{The Data Set: CompuLife Price Quotation System}

We utilized a price quotation system for term insurance called Compulife which has been marketed to US life-insurance agents since 1990. Compulife provides company-specific price quotes for term life-insurance stratified by consumer characteristics (e.g. age, smoking, or state of residence) and type of policies (e.g. length of duration or award size) for a large set of individual companies that sell term-insurance in the US. The life-insurance industry consists of about 1,100 active insurers although the industry is highly concentrated among a dozen large ones. Our sample from Compulife includes about 170 companies or about $15 \%$ of the number of sellers, but it includes many of the larger ones, so it represents well above that percentage in the fraction of policies and amount of coverage sold. The price quotes only concern term insurance, as opposed to whole life insurance. This is desirable because it allows us to more directly infer estimates of mortality. ${ }^{17}$ The data used to provide our price estimates was extracted from the data base of Compulife. The exhaustive list of priced covariates on the consumer side were gender, smoking-status, preferred health status, and age, so that for a given age there were 8 possible combinations of these covariates. The contract information includes price $(p)$, award size $(z)$, and duration $(\tau)$. One important aspect of the price quotes of Compulife is that they only concern contracts of one, five, ten, fifteen and twenty year durations.

Our data cover the years 1990 to 1996, making within sample comparisons possible across six years. One year contracts have been excluded because they represent a very select subgroup of the insured population. ${ }^{18}$ Additionally, we concentrate our analysis on non-preferred status contracts. We feel that the population covered by non-prefered contracts, which is the vast majority of the insured population, is more representative of the population as a whole. ${ }^{19}$ To analyze pure term-contracts, we also excluded any contracts with added features such as a renewability option, since the premia paid for such contracts reflect issues in addition to mortality. Table $1 \mathrm{~A}$ and $1 \mathrm{~B}$ summarize the data in terms of providing the mean prices and their standard

\footnotetext{
${ }^{17}$ Whole life insurance invests a portion of the premia separately and therefore the premia charged are not only dependent on the outlays due to mortality but also highly contingent on the returns on the particular side-investments offered.

${ }^{18}$ See e.g. LIMRA(1994).

${ }^{19}$ Preferred contracts are issued to individuals in particularly good health.
} 
errors across firms.

Table $1 \mathrm{~A}$ provides cohort specific prices for the shortest contract duration, 5 years, while Table $1 \mathrm{~B}$ covers the longest contract duration, 20 years. Within each duration, the prices for the smallest and largest award sizes we consider, $100 \mathrm{~K}$ and $2,500 \mathrm{~K}$, are displayed for each gender and smoking combination. The purpose of this table is to display that these average prices differ across groups of differential mortality in predictable ways. In particular, the following patterns emerge holding other factors constant: smokers face higher premia than non-smokers; premia rise with contract duration; males face higher premia than females; and premia rise less than linearly in award size. More importantly, the cohort specific patterns show that within each covariate category, premia fall with more recent cohorts. Indeed, the estimates of large reductions in hazard rates across cohorts obtained later stems from the basic patterns in these raw data on average prices. Roughly speaking, prices drop between 15 to 30 percent over the six years in our sample. In general, these patterns hold for all contract durations, award sizes, and priced covariates of consumers. In summary, these comparisons of mean prices are consistent on an aggregate level with the notion underlying this paper; competitive prices of mortality contingent claims reflect mortality in predictable ways.

We use these data to estimate the vector of survival parameters, $\theta$, using the appropriate discount rates, $R(t)$, in the market when the cohort was observed. Note that since the premia and awards are both nominal, it is essential to have the nominal discount rate. We computed the nominal discount rate from the nominal zero coupon (strip) bond prices corresponding to the release dates of the insurance data, November 1 in the years 1990-95 and May 1, 1996 as reported in the Wall Street Journal on those particular dates.

\subsection{Cohort Specific Declines in Mortality}

In studying cohort effects on mortality, one attempts to control for all differences in prices across cohorts except the year of birth of the insured individual. In particular, we want to hold the type of contract and the type 
of customer, apart from year of birth, the same. It is very important to avoid comparing cohorts across both ages and calendar time. This type of comparison is important to avoid because life-insurance companies exclude high risk individuals in contracting. For example, it is generally true that a long term contract for a given duration costs more than a sequence of short term contracts over the same duration. This discrepancy exists because the sequence of recontracting in the later case allows the insurance companies to exclude individuals who become high risks. These exclusions may have big effects on the premium of the long term contract, even though the fraction excluded is small, because the relative risks are often enormous. Middle aged individuals are well below one percent in hazard rates, so the hazard rates of high risk individuals are often many multiples of those of low risk individuals. We will therefore adopt the strategy of estimating cohort survivals at different calendar times. This is important because it avoids such recontracting issues by enabling one to get age specific survivals for the same ages across different cohorts.

For each cohort that turned 60 between 1990 and 1996, which are those born in 1930 through 1936, we estimate the survival function conditional on reaching age 60 with the Compulife data and estimation technique described above.

Table $2 \mathrm{~A}$ and $2 \mathrm{~B}$ display our parameter estimates for the survival function and the award specific costs of production for females and males, respectively.

The costs associated with any given contract routinely fall between one and two percent of the face value of the contract with standard errors of approximately 10 percent of the point estimates. These magnitudes imply that the costs as a percentage of premia compare with documented production costs of the previously discussed term-insurance industry in 1994 of about 11 percent. Since we are constraining the costs to be the same across all durations, we understate costs on long-term contracts and over-state them on short term contracts. For example, for female non-smokers born in 1930, and hence turning 60 in 1990, the discounted value of premia on a 20 year contract with an award size of $100 \mathrm{~K}$ is around $15 \mathrm{~K}$, which implies that the fixed cost is about 10 percent of the premia.

It is clear that for both females and males the point estimates of $\theta$ are noisy. The standard errors range from 25 to 100 percent of the point estimates 
for $\theta_{1}$, the intercept or baseline hazard rate, and from 2 to 6 percent of the point estimates for $\theta_{2}$, the growth rate of the hazard function. It is important to note that, as expected, the covariance between the point estimates for $\theta_{1}$ and $\theta_{2}$ is large and negative. So, the data are unable to differentiate a low intercept, high growth rate hazard function from a high intercept, low growth rate hazard function. Despite this ambiguity, as will be discussed at length later, the survival functions over a twenty year horizon implied by these estimates are relatively stable and produce the expected increases in survival across the cohorts.

Before discussing how the estimates compare across cohorts, Figure 2 displays how these estimates vary within a given cohort. Figure 2 plots the hazard function for the four combinations of gender and smoking present in our data for the 1935 cohort at age 60 . The patterns present in this figure hold for all cohorts analyzed.

These within cohort estimates perform as expected. The hazard rates are lower and, hence, life-expectancies longer for females than males and for non-smokers than smokers. The conformance with expectations of the price estimates of mortality rates within a cohort lend confidence to utilizing the same methods to estimate mortality differences between cohorts.

To illustrate the mortality differences between cohorts, Tables $3 \mathrm{~A}$ and $3 \mathrm{~B}$ display price estimates for the future mortality experience of individuals aged 60 in each of our seven cohorts for non-smoking females and males, respectively. The tables report both age specific hazard rates, $h(t)$, and survival functions, $S(t)$.

Figures $3 \mathrm{~A}$ and $3 \mathrm{~B}$ graphically depict the hazard rates presented in Tables $3 \mathrm{~A}$ and $3 \mathrm{~B}$ for females and males, respectively.

The general pattern is for the hazard functions to be decreasing with each successive cohort. However, as alluded to earlier, the data are unable to accurately differentiate low intercept, high growth rate hazard functions 
from high intercept, low growth rate ones. This failing manifests itself in the hazard functions for 1990 and 1991 for males and 1993 for females. The 1990 hazard function for males has the highest hazard rate at age 60 and the lowest hazard rate at age 80 seen in any of the cohorts. Similarly, the 1991 hazard function for males has the second highest initial hazard rate and a terminal hazard rate below that of the 1992, 1993 and 1994 cohorts. Although less pronounced, the 1993 hazard function for females starts above and finishes below the 1994 hazard function.

Despite this lack of monotonicity in the reduction of age specific hazard rates across cohorts, the survival functions implied by these hazard functions are almost monotonically increasing for the middle ten ages of our sample frame, ages 65 to 74 . It is not surprising that this relationship breaks down near the tails of the sample frame, given that we have imposed a parametric form on the survival function. Furthermore, given that the estimates are behaving poorly by age 80 , we strongly advise the reader to concentrate on the results for ages 65 to 74 and not to extrapolate these estirnates outside of the sample frame.

The next question is how do our estimates of cohort-specific reductions in mortality compare with out of sample experience. In other words, we are interested in how the future mortality declines implicit in market prices compare to historical trends. Kannisto et al (1994) has documented that for a large set of European countries, for which historical mortality data is good, the percentage drop in age-specific hazard rates is in the range of 2 5 percent per cohort. To investigate how these yearly percentage declines in hazard rates compare with our estimates, consider a proportional hazard model where the hazard function of the cohort born in year $y$ satisfies

$$
h_{y}(t)=(1-d)^{y} h_{o}(t)
$$

where $d$ is the per-cohort percentage decrease in the hazard function and $h_{o}(t)$ is the assumed underlying baseline shape of all cohorts. The corresponding survivals across cohorts are related as in

$$
S_{y}(t)=\left[S_{o}(t)\right]^{(1-d)^{y}}
$$

where $S_{o}(t)$ is the baseline survival function. The evidence of Kannisto et al (1994) suggests that this proportional drop in hazard rates is between 2 and 5 percent per cohort, $0.02 \leq d \leq 0.05$. To compare this to our estimates, 
we compute what the hazard and survival rates would have been applying a yearly reduction in hazards of 5 percent, taking the first year of the data, 1990, as the baseline shape of all cohorts. Tables $4 \mathrm{~A}$ and $4 \mathrm{~B}$ display these computations.

Compare the survival functions estimated for 1996 with the price data (the lower panels of Tables 3A and 3B) to those computed from the 1990 estimates assuming a 5 percent reduction per cohort in hazard rates (the lower panels of Tables $4 \mathrm{~A}$ and $4 \mathrm{~B}$ ). These two sets of estimates are very similar. For females, the survival curve assuming a 5 percent per cohort reduction starts slightly above the curve derived from the 1996 price data, but finishes below it (crossing at age 75). For males the pattern is reversed, starting below and finishing above (crossing at age 70). The curves cross because the shape of the hazard function estimated from the 1990 price data differs from that of the hazard function estimated from the 1996 data. Thus, our estimates of cohort specific reductions in mortality in the future are in the upper range of those observed in the past.

\section{Concluding Remarks}

This paper takes advantage of the identification induced by competitive pricing to infer from mortality contingent claim prices, in particular term life insurance contracts, the implicit expectations of future old-age longevity. We show that the competitive pricing restrictions used to identify mortality produce results that mimic the pattern and magnitude of previously observed mortality. Our main finding is that life insurance companies expect mortality to continue to decline at rates close to or slightly in excess of historical estimates of decline. In particular, prices reveal that the market expects hazard functions of insured individuals to decline on average around 5 percent annually. Although the patterns in the data seem clear on a continued decline, the cellsizes of our particular data have problems distinguishing small differences in magnitudes with any precision. This implies that between consecutive cohorts, the differences are insignificant, but between longer spaced cohorts 
they are significant. The implications of these future continued mortality reductions for expenditures on old-age public programs, holding the program laws constant through time, may therefore be important.

We conclude by discussing future research on this matter and questions that may be addressed utilizing similar techniques to those developed here.

\subsection{Private vs. Public Mortality Projections}

There are several projections of mortality offered by public agencies such as SSA and the Census in the US. Although no comparable projections that differ widely from those of SSA and the Census have been proposed, recent research by Manton et al (1996) argues that mortality patterns may be better forecast if the covariates of mortality were better forecast, and the corresponding mortality conditional on those covariates were better understood. This method differs from classical mortality projections which fit statistical models to a time series of aggregate mortality without conditioning. In particular, SSA and the Census Bureau use such extrapolations to generate mortality forecasts that are used to determine the solvency of Social Security and Medicare. The Census Bureau generally obtain lower mortality rates than the SSA. Furthermore, Lee (1990) has fit a univariate time trend across cohorts to age specific hazard rates over time and projected mortality rates to be similar to the middle range longevity estimates of the Census Bureau and the upper range of the SSA.

In comparing our estimates with those of public agencies or demographers, a few notes are in order. First, the population for which mortality is estimated differs between the two; the insured population and the entire population, respectively. However, we are able to compare the experienced mortality of these two population in 1980, the latest year for which CSO Tables have been published. Figures $4 \mathrm{~A}$ and $4 \mathrm{~B}$ display the conditional lifeexpectancy for the CSO in 1980 with the corresponding cross-section for SSA in 1980 for females and males, respectively.

As the figures illustrate life-expectancy is higher for those that demand life-insurance relative to the population as a whole. However, the differences between insured mortality and SSA mortality is not dramatic. The percentage increase in life-expectancy in going from the overall population to 
the insured population is indeed small, especially in relation to long-spaced cohort differences. Given these relatively small differences between the insured and overall population, our estimates of mortality levels may not differ greatly from those of the overall population. Furthermore, if the demand for insurance does not interact with the level of mortality, our estimates of the rates of decline in mortality will be similar to those in the overall population. There are few theoretical reasons to believe that those who demand insurance have mortality that declines at a different rate from those without insurance. ${ }^{20}$

\subsection{Data Quality in Surveys versus Market Prices}

There are several data production issues that separate the market based estimates of mortality from estimates based on population surveys. First, our estimates only concern the mortality of the insured population. To generalize to other populations, one needs to correct for how uninsured individuals differ from insured individuals. However, even though the levels of mortality may differ across the insured and the overall populations, there is less reason to believe that the rates of change across cohorts should differ. However, issues of selection are important here, particularly when mortality is dependent on the mornent conditions through contract types. However, recent evidence by Cawley and Philipson (1996) has documented evidence for the term-insurance market consistent with the idea that there is no selection across contracts on self-perceived mortality.

There are several reasons why the quality of mortality estimates from life-insurance premia may be superior to population based surveys, holding the population sampled constant. First, life-insurance data is less likely to have measurement error. Deaths of those with life-insurance have stronger incentives to be reported than do deaths in surveys since the beneficiaries forego the face value of the policy when death is not adequately documented. In other words, non-response is very costly for the population on whom

\footnotetext{
${ }^{20} \mathrm{Our}$ forecasts are also limited by contract durations. Although 20 or 30 year forecasts might be reasonable, we feel that forecasts beyond 30 years may be overly ambitious. In this regard it is interesting to note that only in the public sector do such long range mortality forecasts take place, perhaps because the cost-benefit ratio for such forecasting does not meet market standards. Indeed, no one in 1930 could predict even the factors, let alone their levels, that affected mortality in 1980 or 1990 .
} 
mortality is measured. Furthermore, since premia are increasing in age, insurers validate age more extensively than most surveys. Second, the base on which mortality rates are computed is better defined than the base for public surveys or censuses. In such surveys or censuses, this base is often uncertain due to non-coverage of the sample frame or non-response of sample members. However, for mortality contingent claims, the base is the set of initial policy holders which is always fully observed. Third, missing data in surveys may be due to either mortality or living attrition. Hence, surveys are forced to take a stand on what fraction of the missing observations represent mortality and this is done by definition without knowledge about how accurate this stand is.

Data quality, and forecasting in general, should of course be evaluated by its performance. An important issue that we could not address with these data was evaluating the market forecasts through within or out-ofsample performance. Our paper focused on what could be identified from prices without fully being able to evaluate the performance of the estimates obtained. Clearly such performance tests should be performed if the data is available to do it, which unfortunately is not the case here. Unfortunately, other forecasts of mortality have not been evaluated within sample either. An important avenue of future research is therefore to evaluate the relative performance of our estimates and those of other methods. 


\section{References}

[1] Aaron, H., Bosworth, B., and G., Burtless, (1989), Can America Afford to Grow Old? Paying for Social Security, The Brookings Institution, Washington, DC.

[2] American Council of Life Insurance, 1994 Life Insurance Fact Book.

[3] Cawley, J., and T., Philipson, (1996), 'An Empirical Examination of Information Barriers to Trade in Mortality Contingent Insurance', $\mathrm{Na}$ tional Bureau of Economic Research, Working Paper No 5669.

[4] Clark., R., Kreps, J., and J., Spengler, (1978), 'Economics of Aging: A Survey', Journal of Economic Literature, p 919-62.

[5] Congressional Budget Office, (1993), 'Baby Boomers in Retirement: An Early Perspective', Washington, DC.

[6] Fogel, Robert W. "Economic Growth, Population Theory, and Physiology: The Bearing of Long-Term Processes on the Making of Economic Policy." American Economic Review, 84(3), June 1994: 369-95.

[7] Hansen, L., (1982), 'Large Sample Properties of Generalized Methods of Moments Estimators' Econometrica, 50, 1029-54

[8] Kannisto, V., J. Lauritsen, R. Thatcher, and J. Vaupel, (1994), 'Reductions in Mortality at Advanced Ages: Several Decades of Evidence from 27 Countries', Population and Development Review, 20, 4, 793-810.

[9] Lee, R., and Tuljapurkar, S., (1994), ' Stochastic Population Forecasts for the United States: Beyond High, Medium, and Low, Journal of the American Statistical Association, v 89 n 428, pp. 1175-89.

[10] Life-Insurance Research and Marketing Association (LIMRA), (1994), The Buyers Stydy, Hartford, Connecticut.

[11] Manton, Kenneth G. and Eric Stallard, (1984), Recent Trends in Mortality Analysis, Orlando, FL: Academic Press. 
[12] Manton, K., E., Stallard, and B. Singer , (1996), 'Longevity in The United States: Age and Sex-Specific Evidence on Life Span Limits From Mortality Patterns 1960-1990', Journal of Gerontology, v 51A, No 5, B362-75.

[13] Olshansky, J., (1988), 'On Forecasting Mortality', The Milibank Quarterly, v 66, pp482-530.

[14] Philipson, T., and R., Posner, (1993), Private Choices and Public Health: An Economic Approach to The AIDS Epidemic, Cambridge and London: Harvard University Press.

[15] Posner, R., (1995), Aging and Old Age, Chicago: University of Chicago Press.

[16] Rosenzweigh, M., and O., Stark, (1995), Handbook of Population and Family Economics, New York: North-Holland.

[17] Skinner, J., and , R., Lee (1996), 'Assessing Forecats of Mortality, Health Status, and Health Costs During Baby Boomers' Retirement', in Assessing Knowledge about Retirement Behavior, Washington, DC.

[18] Skinner, J., (1985), ' The Effect of Increased Longevity on Capital Accumulation', American Economic Review, v 75, No 5, 1143-50/

[19] Skinner, J., (1991), 'Individaul Retirement Accounts; A Review of The Evidence', National Bureau of Economic Research, Working Paper No 3938.

[20] World Bank, (1984), Demographic Change and Public Policy, World Development Report, Washington, DC, Oxford University Press.

[21] Wright, K., (1992), The Life Insurance Industry in The United States : An Analysis of Economic and Regulatory Issues, Working Paper, Coultry Economics Department, The World Bank.

[22] Vaupel, J., (1986), 'How Changes in Age-Specific Mortality Affects LifeExpectancy', Population Studies, 40, 147-57. 


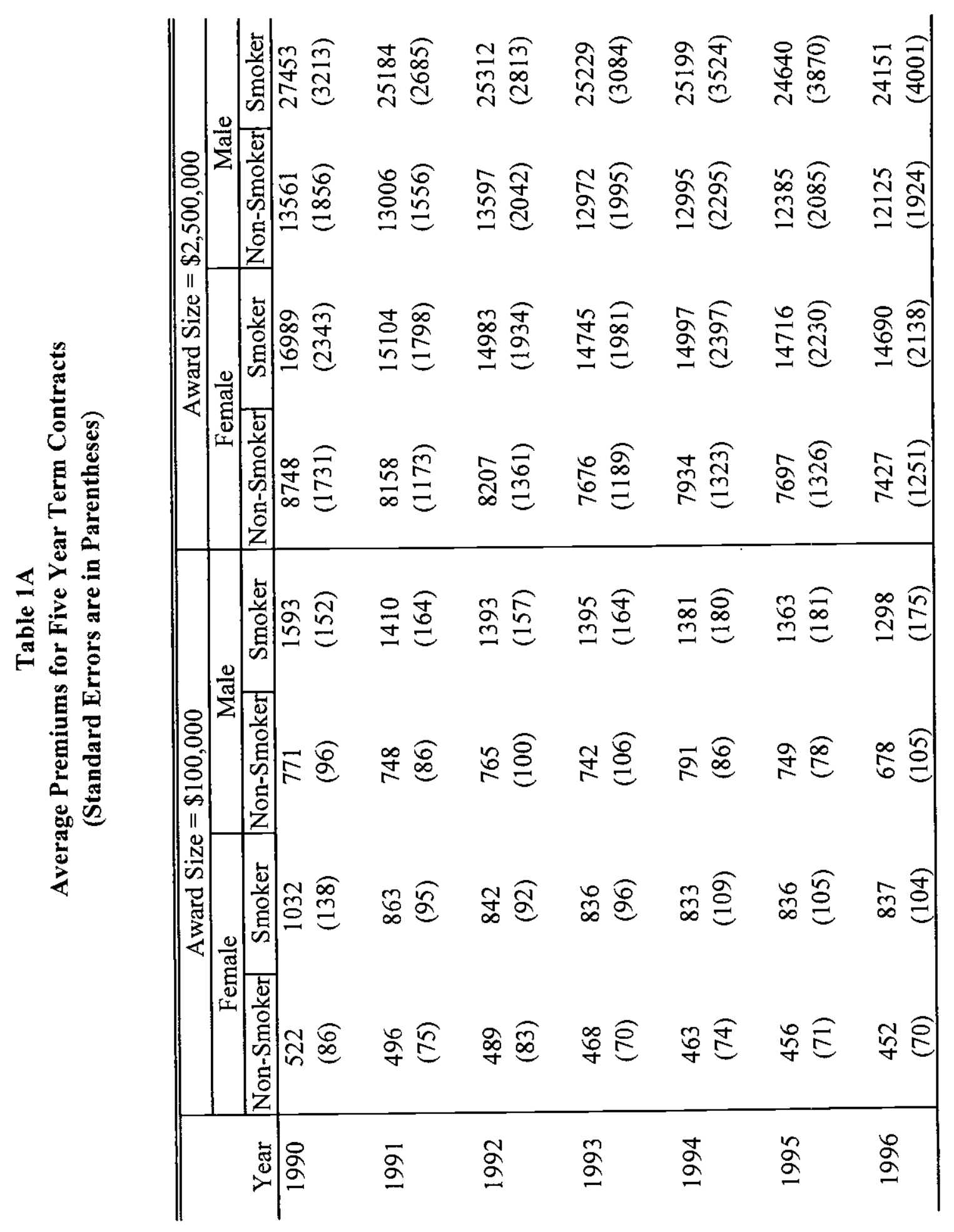




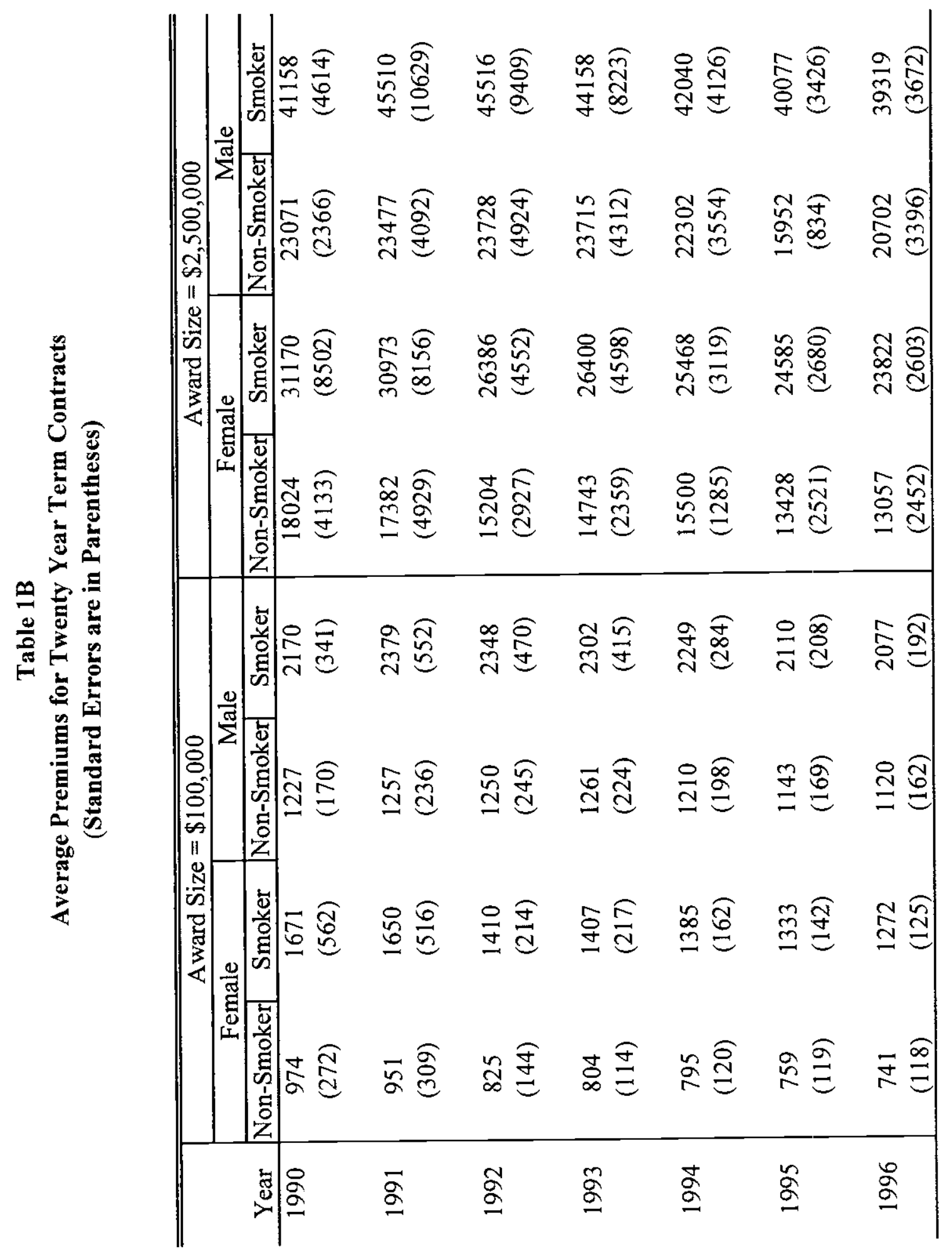


Table 2A

GMM Estimates of Survival Function Parameters and Fixed Costs

Females at Age 60

(Standard Errors in Parentheses)

\begin{tabular}{|c|c|c|c|c|c|c|c|c|c|}
\hline \multirow[b]{2}{*}{ Smoker } & \multirow[b]{2}{*}{ Year } & \multicolumn{2}{|c|}{ Survival Parameters* } & \multicolumn{6}{|c|}{ Costs } \\
\hline & & $\theta_{1}$ & $\theta_{2}$ & 100,000 & 500,000 & $1,000,000$ & $1,500,000$ & $2,000,000$ & $2,500,000$ \\
\hline No & 1990 & $\begin{array}{c}2.49 \\
(2.22)\end{array}$ & $\begin{array}{l}17.61 \\
(1.19)\end{array}$ & $\begin{array}{r}1489 \\
(109)\end{array}$ & $\begin{array}{l}5554 \\
(592)\end{array}$ & $\begin{array}{c}10732 \\
(1178)\end{array}$ & $\begin{array}{c}15995 \\
(1770)\end{array}$ & $\begin{array}{l}21248 \\
(2359)\end{array}$ & $\begin{array}{l}26501 \\
(2949)\end{array}$ \\
\hline & 1991 & $\begin{array}{c}6.34 \\
(4.57)\end{array}$ & $\begin{array}{l}16.41 \\
(0.97)\end{array}$ & $\begin{array}{l}1188 \\
(101)\end{array}$ & $\begin{array}{l}3761 \\
(492)\end{array}$ & $\begin{array}{c}7281 \\
(964)\end{array}$ & $\begin{array}{l}10791 \\
(1446)\end{array}$ & $\begin{array}{l}14300 \\
(1928)\end{array}$ & $\begin{array}{l}17810 \\
(2410)\end{array}$ \\
\hline & 1992 & $\begin{array}{l}20.02 \\
(7.28)\end{array}$ & $\begin{array}{l}14.83 \\
(0.47)\end{array}$ & $\begin{array}{l}1141 \\
(77)\end{array}$ & $\begin{array}{l}3391 \\
(357)\end{array}$ & $\begin{array}{l}6475 \\
(710)\end{array}$ & $\begin{array}{c}9581 \\
(1064)\end{array}$ & $\begin{array}{l}12686 \\
(1418)\end{array}$ & $\begin{array}{l}15930 \\
(1769)\end{array}$ \\
\hline & 1993 & $\begin{array}{c}45.93 \\
(13.09)\end{array}$ & $\begin{array}{l}13.64 \\
(0.36)\end{array}$ & $\begin{array}{l}1114 \\
(70)\end{array}$ & $\begin{array}{l}3102 \\
(330)\end{array}$ & $\begin{array}{l}5775 \\
(650)\end{array}$ & $\begin{array}{l}8507 \\
(974)\end{array}$ & $\begin{array}{l}11240 \\
(1298)\end{array}$ & $\begin{array}{c}14014 \\
(1620)\end{array}$ \\
\hline & 1994 & $\begin{array}{c}9.21 \\
(2.70)\end{array}$ & $\begin{array}{l}15.67 \\
(0.37)\end{array}$ & $\begin{array}{l}1212 \\
(58)\end{array}$ & $\begin{array}{l}4116 \\
(262)\end{array}$ & $\begin{array}{r}7905 \\
(516)\end{array}$ & $\begin{array}{l}12360 \\
(723)\end{array}$ & $\begin{array}{c}16381 \\
(964)\end{array}$ & $\begin{array}{l}20403 \\
(1206)\end{array}$ \\
\hline & 1995 & $\begin{array}{l}22.07 \\
(6.04)\end{array}$ & $\begin{array}{l}14.38 \\
(0.35)\end{array}$ & $\begin{array}{l}1236 \\
(54)\end{array}$ & $\begin{array}{l}4146 \\
(247)\end{array}$ & $\begin{array}{l}7701 \\
(493)\end{array}$ & $\begin{array}{l}12102 \\
(678)\end{array}$ & $\begin{array}{l}16034 \\
(904)\end{array}$ & $\begin{array}{l}19965 \\
(1131)\end{array}$ \\
\hline & 1996 & $\begin{array}{c}18.67 \\
(5.18)\end{array}$ & $\begin{array}{l}14.56 \\
(0.35)\end{array}$ & $\begin{array}{l}1263 \\
(49)\end{array}$ & $\begin{array}{l}4169 \\
(232)\end{array}$ & $\begin{array}{c}7677 \\
(451)\end{array}$ & $\begin{array}{l}11796 \\
(635)\end{array}$ & $\begin{array}{l}15610 \\
(848)\end{array}$ & $\begin{array}{l}19424 \\
(1062)\end{array}$ \\
\hline Yes & 1990 & $\begin{array}{c}7.59 \\
(7.86)\end{array}$ & $\begin{array}{l}16.87 \\
(1.39)\end{array}$ & $\begin{array}{l}2525 \\
(212)\end{array}$ & $\begin{array}{c}9771 \\
(1018)\end{array}$ & $\begin{array}{c}19341 \\
(1996)\end{array}$ & $\begin{array}{l}28889 \\
(2994)\end{array}$ & $\begin{array}{l}38436 \\
(3993)\end{array}$ & $\begin{array}{l}47983 \\
(4992)\end{array}$ \\
\hline & 1991 & $\begin{array}{c}4.07 \\
(3.21)\end{array}$ & $\begin{array}{l}17.73 \\
(1.07)\end{array}$ & $\begin{array}{l}2136 \\
(151)\end{array}$ & $\begin{array}{r}7717 \\
(754)\end{array}$ & $\begin{array}{l}14924 \\
(1513)\end{array}$ & $\begin{array}{l}22261 \\
(2269)\end{array}$ & $\begin{array}{l}29598 \\
(3025)\end{array}$ & $\begin{array}{l}36935 \\
(3781)\end{array}$ \\
\hline & 1992 & $\begin{array}{c}50.44 \\
(25.13)\end{array}$ & $\begin{array}{l}14.36 \\
(0.65)\end{array}$ & $\begin{array}{l}1557 \\
(150)\end{array}$ & $\begin{array}{c}5491 \\
(778)\end{array}$ & $\begin{array}{l}10620 \\
(1563)\end{array}$ & $\begin{array}{l}15807 \\
(2341)\end{array}$ & $\begin{array}{l}20994 \\
(3120)\end{array}$ & $\begin{array}{l}26267 \\
(3898)\end{array}$ \\
\hline & 1993 & $\begin{array}{l}23.66 \\
(9.77)\end{array}$ & $\begin{array}{l}15.20 \\
(0.53)\end{array}$ & $\begin{array}{l}2007 \\
(136)\end{array}$ & $\begin{array}{l}7418 \\
(701)\end{array}$ & $\begin{array}{l}14124 \\
(1408)\end{array}$ & $\begin{array}{l}21048 \\
(2109)\end{array}$ & $\begin{array}{l}27973 \\
(2810)\end{array}$ & $\begin{array}{l}34898 \\
(3511)\end{array}$ \\
\hline & 1994 & $\begin{array}{c}5.07 \\
(1.90)\end{array}$ & $\begin{array}{l}17.13 \\
(0.48)\end{array}$ & $\begin{array}{l}2326 \\
(116)\end{array}$ & $\begin{array}{l}9283 \\
(587)\end{array}$ & $\begin{array}{l}17911 \\
(1164)\end{array}$ & $\begin{array}{l}27401 \\
(1763)\end{array}$ & $\begin{array}{l}36435 \\
(2348)\end{array}$ & $\begin{array}{l}45468 \\
(2932)\end{array}$ \\
\hline & 1995 & $\begin{array}{c}17.02 \\
(5.93)\end{array}$ & $\begin{array}{l}15.40 \\
(0.44)\end{array}$ & $\begin{array}{l}2349 \\
(112)\end{array}$ & $\begin{array}{l}9044 \\
(556)\end{array}$ & $\begin{array}{l}17331 \\
(1127)\end{array}$ & $\begin{array}{l}26354 \\
(1717)\end{array}$ & $\begin{array}{l}35036 \\
(2287)\end{array}$ & $\begin{array}{l}43832 \\
(2934)\end{array}$ \\
\hline & 1996 & $\begin{array}{c}9.26 \\
(4.00)\end{array}$ & $\begin{array}{l}16.14 \\
(0.55)\end{array}$ & $\begin{array}{l}2455 \\
(111)\end{array}$ & $\begin{array}{l}9758 \\
(556)\end{array}$ & $\begin{array}{l}18900 \\
(1132)\end{array}$ & $\begin{array}{l}28624 \\
(1720) \\
\end{array}$ & $\begin{array}{l}38062 \\
(2292) \\
\end{array}$ & $\begin{array}{l}47602 \\
(2915)\end{array}$ \\
\hline
\end{tabular}

* These paraemters are measured in e-7 and e-2, respectively. 
Table $2 \mathrm{~B}$

GMM Estimates of Survival Function Parameters and Fixed Costs

Males at Age 60

(Standard Errors in Parentheses)

\begin{tabular}{|c|c|c|c|c|c|c|c|c|c|}
\hline \multirow[b]{2}{*}{ Smoker } & \multirow[b]{2}{*}{ Year } & \multicolumn{2}{|c|}{ Survival Parameters* } & \multicolumn{6}{|c|}{ Costs } \\
\hline & & $\theta_{1}$ & $\theta_{2}$ & 100,000 & 500,000 & $1,000,000$ & $1,500,000$ & $2,000,000$ & $2,500,000$ \\
\hline \multirow[t]{7}{*}{ No } & 1990 & $\begin{array}{r}1158.10 \\
(695.45)\end{array}$ & $\begin{array}{l}10.21 \\
(0.76)\end{array}$ & $\begin{array}{c}953 \\
(169)\end{array}$ & 2488 & $\begin{array}{c}4871 \\
(1756)\end{array}$ & $\begin{array}{c}7207 \\
(2635)\end{array}$ & $\begin{array}{c}9543 \\
(3513)\end{array}$ & $\begin{array}{l}11880 \\
(4391)\end{array}$ \\
\hline & 1991 & $\begin{array}{c}417.35 \\
(237.29)\end{array}$ & $\begin{array}{l}11.54 \\
(0.74)\end{array}$ & $\begin{array}{c}916 \\
(148)\end{array}$ & $\begin{array}{l}2009 \\
(742)\end{array}$ & $\begin{array}{c}3899 \\
(1486)\end{array}$ & $\begin{array}{c}5727 \\
(2230)\end{array}$ & $\begin{array}{c}7555 \\
(2974)\end{array}$ & $\begin{array}{c}9383 \\
(3719)\end{array}$ \\
\hline & 1992 & $\begin{array}{c}61.53 \\
(24.12)\end{array}$ & $\begin{array}{l}14.06 \\
(0.51)\end{array}$ & $\begin{array}{l}1315 \\
(117)\end{array}$ & $\begin{array}{l}4128 \\
(616)\end{array}$ & $\begin{array}{c}7945 \\
(1237)\end{array}$ & $\begin{array}{l}11180 \\
(1874)\end{array}$ & $\begin{array}{l}15602 \\
(2476)\end{array}$ & $\begin{array}{c}19482 \\
(3100)\end{array}$ \\
\hline & 1993 & $\begin{array}{c}59.83 \\
(18.58)\end{array}$ & $\begin{array}{l}13.99 \\
(0.40)\end{array}$ & $\begin{array}{l}1575 \\
(107)\end{array}$ & $\begin{array}{l}4751 \\
(548)\end{array}$ & $\begin{array}{c}9263 \\
(1082)\end{array}$ & $\begin{array}{l}13735 \\
(1624)\end{array}$ & $\begin{array}{l}18206 \\
(2166)\end{array}$ & $\begin{array}{l}22722 \\
(2710)\end{array}$ \\
\hline & 1994 & $\begin{array}{c}53.62 \\
(15.13)\end{array}$ & $\begin{array}{l}14.06 \\
(0.36)\end{array}$ & $\begin{array}{c}1532 \\
(107)\end{array}$ & $\begin{array}{l}4981 \\
(519)\end{array}$ & $\begin{array}{c}9198 \\
(1016)\end{array}$ & $\begin{array}{l}14498 \\
(1528)\end{array}$ & $\begin{array}{l}21656 \\
(1982)\end{array}$ & $\begin{array}{l}23920 \\
(2546)\end{array}$ \\
\hline & 1995 & $\begin{array}{l}178.35 \\
(40.04)\end{array}$ & $\begin{array}{l}12.37 \\
(0.28)\end{array}$ & $\begin{array}{l}1386 \\
(94)\end{array}$ & $\begin{array}{l}4409 \\
(441)\end{array}$ & $\begin{array}{l}7960 \\
(862)\end{array}$ & $\begin{array}{l}12240 \\
(1291)\end{array}$ & $\begin{array}{l}16494 \\
(1766)\end{array}$ & $\begin{array}{l}20148 \\
(2149)\end{array}$ \\
\hline & 1996 & $\begin{array}{l}108.93 \\
(24.77)\end{array}$ & $\begin{array}{l}12.98 \\
(0.29)\end{array}$ & $\begin{array}{l}1482 \\
(83)\end{array}$ & $\begin{array}{l}4890 \\
(389)\end{array}$ & $\begin{array}{l}8915 \\
(754)\end{array}$ & $\begin{array}{l}13535 \\
(1141)\end{array}$ & $\begin{array}{l}17910 \\
(1521)\end{array}$ & $\begin{array}{l}22515 \\
(1885)\end{array}$ \\
\hline \multirow[t]{7}{*}{ Yes } & 1990 & $\begin{array}{c}2307.10 \\
(1466.60)\end{array}$ & $\begin{array}{l}10.03 \\
(0.81)\end{array}$ & $\begin{array}{l}2092 \\
(289)\end{array}$ & $\begin{array}{c}7193 \\
(1448)\end{array}$ & $\begin{array}{l}13814 \\
(2866)\end{array}$ & $\begin{array}{l}20594 \\
(4301)\end{array}$ & $\begin{array}{l}27373 \\
(5735)\end{array}$ & $\begin{array}{l}34152 \\
(7170)\end{array}$ \\
\hline & 1991 & $\begin{array}{c}141.06 \\
(146.63)\end{array}$ & $\begin{array}{l}13.71 \\
(1.38)\end{array}$ & $\begin{array}{l}2409 \\
(344)\end{array}$ & $\begin{array}{c}8168 \\
(1691)\end{array}$ & $\begin{array}{l}15849 \\
(3360)\end{array}$ & $\begin{array}{l}23642 \\
(5040)\end{array}$ & $\begin{array}{l}31436 \\
(6719)\end{array}$ & $\begin{array}{l}39238 \\
(8446)\end{array}$ \\
\hline & 1992 & $\begin{array}{c}9.45 \\
(3.87)\end{array}$ & $\begin{array}{l}17.31 \\
(0.55)\end{array}$ & $\begin{array}{l}3061 \\
(176)\end{array}$ & $\begin{array}{l}12332 \\
(860)\end{array}$ & $\begin{array}{l}24259 \\
(1697)\end{array}$ & $\begin{array}{l}36232 \\
(2545)\end{array}$ & $\begin{array}{l}48205 \\
(3394)\end{array}$ & $\begin{array}{l}60173 \\
(4244)\end{array}$ \\
\hline & 1993 & $\begin{array}{l}13.28 \\
(4.39)\end{array}$ & $\begin{array}{l}16.75 \\
(0.44)\end{array}$ & $\begin{array}{l}3318 \\
(173)\end{array}$ & $\begin{array}{c}13220 \\
(852)\end{array}$ & $\begin{array}{l}25496 \\
(1682)\end{array}$ & $\begin{array}{l}38068 \\
(2522)\end{array}$ & $\begin{array}{l}50641 \\
(3363)\end{array}$ & $\begin{array}{l}63247 \\
(4207)\end{array}$ \\
\hline & 1994 & $\begin{array}{l}36.42 \\
(9.94)\end{array}$ & $\begin{array}{l}15.38 \\
(0.36)\end{array}$ & $\begin{array}{l}2972 \\
(150)\end{array}$ & $\begin{array}{l}11665 \\
(739)\end{array}$ & $\begin{array}{l}22154 \\
(1467)\end{array}$ & $\begin{array}{l}33882 \\
(2223)\end{array}$ & $\begin{array}{l}45060 \\
(2964)\end{array}$ & $\begin{array}{l}56237 \\
(3705)\end{array}$ \\
\hline & 1995 & $\begin{array}{l}273.60 \\
(66.74)\end{array}$ & $\begin{array}{l}12.65 \\
(0.31)\end{array}$ & $\begin{array}{l}2547 \\
(177)\end{array}$ & $\begin{array}{l}8770 \\
(888)\end{array}$ & $\begin{array}{l}15500 \\
(1780)\end{array}$ & $\begin{array}{l}23618 \\
(2680)\end{array}$ & $\begin{array}{l}31350 \\
(3573)\end{array}$ & $\begin{array}{l}39112 \\
(4478)\end{array}$ \\
\hline & 1996 & $\begin{array}{l}184.66 \\
(62.86)\end{array}$ & $\begin{array}{l}13.08 \\
(0.43)\end{array}$ & $\begin{array}{l}2684 \\
(197)\end{array}$ & $\begin{array}{l}10547 \\
(1008)\end{array}$ & $\begin{array}{l}19859 \\
(2037)\end{array}$ & $\begin{array}{l}29633 \\
(3067)\end{array}$ & $\begin{array}{r}39385 \\
(4089) \\
\end{array}$ & $\begin{array}{r}48904 \\
(5172) \\
\end{array}$ \\
\hline
\end{tabular}

* These paraemters are measured in e-7 and e-2, respectively. 
Table 3A

Female Non-Smokers

\begin{tabular}{c|ccccccc}
\hline \hline & \multicolumn{7}{|c}{ Hazard Rates Measured in Percent } \\
Age & 1990 & 1991 & 1992 & 1993 & 1994 & 1995 & 1996 \\
\hline 60 & 0.17 & 0.20 & 0.22 & 0.23 & 0.17 & 0.18 & 0.17 \\
61 & 0.20 & 0.23 & 0.25 & 0.26 & 0.20 & 0.20 & 0.20 \\
62 & 0.24 & 0.27 & 0.29 & 0.30 & 0.24 & 0.24 & 0.23 \\
63 & 0.29 & 0.32 & 0.34 & 0.34 & 0.28 & 0.27 & 0.26 \\
64 & 0.34 & 0.38 & 0.39 & 0.39 & 0.33 & 0.31 & 0.30 \\
65 & 0.41 & 0.45 & 0.46 & 0.45 & 0.38 & 0.36 & 0.35 \\
66 & 0.49 & 0.52 & 0.53 & 0.51 & 0.45 & 0.42 & 0.41 \\
67 & 0.58 & 0.62 & 0.61 & 0.58 & 0.52 & 0.48 & 0.47 \\
68 & 0.69 & 0.73 & 0.71 & 0.67 & 0.61 & 0.56 & 0.54 \\
69 & 0.83 & 0.86 & 0.83 & 0.77 & 0.72 & 0.65 & 0.63 \\
70 & 0.99 & 1.01 & 0.96 & 0.88 & 0.84 & 0.75 & 0.73 \\
71 & 1.18 & 1.19 & 1.11 & 1.01 & 0.98 & 0.86 & 0.84 \\
72 & 1.40 & 1.40 & 1.29 & 1.16 & 1.15 & 0.99 & 0.97 \\
73 & 1.67 & 1.66 & 1.49 & 1.33 & 1.34 & 1.15 & 1.12 \\
74 & 1.99 & 1.95 & 1.73 & 1.52 & 1.57 & 1.32 & 1.30 \\
75 & 2.38 & 2.30 & 2.01 & 1.74 & 1.84 & 1.53 & 1.50 \\
76 & 2.84 & 2.71 & 2.33 & 2.00 & 2.15 & 1.77 & 1.74 \\
77 & 3.38 & 3.19 & 2.70 & 2.29 & 2.51 & 2.04 & 2.01 \\
78 & 4.03 & 3.76 & 3.13 & 2.62 & 2.94 & 2.35 & 2.33 \\
79 & 4.81 & 4.43 & 3.64 & 3.01 & 3.44 & 2.72 & 2.69 \\
80 & 5.73 & 5.22 & 4.22 & 3.45 & 4.02 & 3.14 & 3.12 \\
\hline
\end{tabular}

\begin{tabular}{c|ccccccc}
\hline \hline & \multicolumn{7}{c}{ Conditional Survival Measured in Percent } \\
Age & 1990 & 1991 & 1992 & 1993 & 1994 & 1995 & 1996 \\
\hline 60 & 100.00 & 100.00 & 100.00 & 100.00 & 100.00 & 100.00 & 100.00 \\
61 & 99.82 & 99.79 & 99.77 & 99.76 & 99.81 & 99.81 & 99.82 \\
62 & 99.59 & 99.54 & 99.50 & 99.48 & 99.59 & 99.59 & 99.61 \\
63 & 99.33 & 99.24 & 99.18 & 99.17 & 99.33 & 99.34 & 99.37 \\
64 & 99.02 & 98.90 & 98.82 & 98.81 & 99.03 & 99.05 & 99.09 \\
65 & 98.65 & 98.49 & 98.40 & 98.40 & 98.68 & 98.71 & 98.76 \\
66 & 98.21 & 98.02 & 97.92 & 97.93 & 98.27 & 98.33 & 98.39 \\
67 & 97.69 & 97.46 & 97.36 & 97.40 & 97.80 & 97.89 & 97.96 \\
68 & 97.07 & 96.81 & 96.72 & 96.79 & 97.25 & 97.38 & 97.47 \\
69 & 96.34 & 96.04 & 95.98 & 96.10 & 96.60 & 96.79 & 96.90 \\
70 & 95.47 & 95.15 & 95.13 & 95.31 & 95.86 & 96.12 & 96.25 \\
71 & 94.45 & 94.11 & 94.16 & 94.41 & 94.99 & 95.36 & 95.50 \\
72 & 93.24 & 92.90 & 93.04 & 93.40 & 93.99 & 94.48 & 94.64 \\
73 & 91.82 & 91.49 & 91.76 & 92.25 & 92.83 & 93.47 & 93.65 \\
74 & 90.16 & 89.86 & 90.29 & 90.95 & 91.49 & 92.33 & 92.52 \\
75 & 88.21 & 87.98 & 88.62 & 89.48 & 89.95 & 91.02 & 91.24 \\
76 & 85.95 & 85.81 & 86.72 & 87.82 & 88.18 & 89.54 & 89.77 \\
77 & 83.33 & 83.32 & 84.57 & 85.96 & 86.15 & 87.85 & 88.11 \\
78 & 80.30 & 80.48 & 82.14 & 83.88 & 83.84 & 85.95 & 86.22 \\
79 & 76.84 & 77.26 & 79.41 & 81.55 & 81.22 & 83.80 & 84.08 \\
80 & 72.90 & 73.63 & 76.36 & 78.97 & 78.25 & 81.38 & 81.68 \\
\hline
\end{tabular}


Table 3B

Male Non-Smokers

\begin{tabular}{c|ccccccc}
\hline \hline & \multicolumn{7}{|c}{ Hazard Rates Measured in Percent } \\
Age & 1990 & 1991 & 1992 & 1993 & 1994 & 1995 & 1996 \\
\hline 60 & 0.54 & 0.49 & 0.40 & 0.37 & 0.35 & 0.37 & 0.34 \\
61 & 0.60 & 0.55 & 0.46 & 0.42 & 0.40 & 0.42 & 0.39 \\
62 & 0.66 & 0.62 & 0.53 & 0.49 & 0.46 & 0.47 & 0.44 \\
63 & 0.73 & 0.69 & 0.61 & 0.56 & 0.53 & 0.54 & 0.50 \\
64 & 0.81 & 0.78 & 0.70 & 0.65 & 0.61 & 0.61 & 0.57 \\
65 & 0.90 & 0.87 & 0.81 & 0.74 & 0.70 & 0.69 & 0.65 \\
66 & 1.00 & 0.98 & 0.93 & 0.85 & 0.81 & 0.78 & 0.74 \\
67 & 1.10 & 1.10 & 1.07 & 0.98 & 0.93 & 0.88 & 0.84 \\
68 & 1.22 & 1.23 & 1.23 & 1.13 & 1.07 & 0.99 & 0.96 \\
69 & 1.35 & 1.38 & 1.42 & 1.30 & 1.24 & 1.13 & 1.09 \\
70 & 1.50 & 1.55 & 1.63 & 1.50 & 1.42 & 1.27 & 1.24 \\
71 & 1.66 & 1.74 & 1.88 & 1.72 & 1.64 & 1.44 & 1.42 \\
72 & 1.84 & 1.96 & 2.16 & 1.98 & 1.88 & 1.63 & 1.61 \\
73 & 2.04 & 2.19 & 2.49 & 2.28 & 2.17 & 1.85 & 1.84 \\
74 & 2.26 & 2.46 & 2.87 & 2.62 & 2.50 & 2.09 & 2.09 \\
75 & 2.50 & 2.76 & 3.30 & 3.01 & 2.87 & 2.36 & 2.38 \\
76 & 2.77 & 3.10 & 3.80 & 3.46 & 3.31 & 2.68 & 2.71 \\
77 & 3.07 & 3.48 & 4.37 & 3.98 & 3.80 & 3.03 & 3.08 \\
78 & 3.40 & 3.91 & 5.03 & 4.58 & 4.38 & 3.43 & 3.51 \\
79 & 3.76 & 4.39 & 5.79 & 5.27 & 5.04 & 3.88 & 4.00 \\
80 & 4.16 & 4.92 & 6.66 & 6.06 & 5.80 & 4.39 & 4.55 \\
\hline
\end{tabular}

\begin{tabular}{c|ccccccc}
\hline \hline & \multicolumn{7}{|c}{ Conditional Survival Measured in Percent } \\
Age & 1990 & 1991 & 1992 & 1993 & 1994 & 1995 & 1996 \\
\hline 60 & 100.00 & 100.00 & 100.00 & 100.00 & 100.00 & 100.00 & 100.00 \\
61 & 99.43 & 99.48 & 99.57 & 99.60 & 99.63 & 99.61 & 99.64 \\
62 & 98.81 & 98.91 & 99.08 & 99.15 & 99.20 & 99.17 & 99.23 \\
63 & 98.12 & 98.26 & 98.52 & 98.63 & 98.71 & 98.67 & 98.76 \\
64 & 97.37 & 97.54 & 97.88 & 98.04 & 98.15 & 98.11 & 98.24 \\
65 & 96.54 & 96.74 & 97.14 & 97.36 & 97.51 & 97.47 & 97.64 \\
66 & 95.62 & 95.85 & 96.30 & 96.59 & 96.77 & 96.77 & 96.96 \\
67 & 94.63 & 94.86 & 95.34 & 95.71 & 95.93 & 95.97 & 96.20 \\
68 & 93.53 & 93.77 & 94.25 & 94.70 & 94.98 & 95.08 & 95.34 \\
69 & 92.33 & 92.55 & 93.02 & 93.56 & 93.89 & 94.07 & 94.37 \\
70 & 91.03 & 91.20 & 91.61 & 92.26 & 92.65 & 92.95 & 93.27 \\
71 & 89.60 & 89.71 & 90.02 & 90.79 & 91.25 & 91.70 & 92.04 \\
72 & 88.05 & 88.07 & 88.22 & 89.13 & 89.66 & 90.31 & 90.66 \\
73 & 86.36 & 86.27 & 86.19 & 87.26 & 87.87 & 88.75 & 89.12 \\
74 & 84.52 & 84.28 & 83.92 & 85.15 & 85.84 & 87.03 & 87.39 \\
75 & 82.54 & 82.11 & 81.38 & 82.79 & 83.57 & 85.11 & 85.46 \\
76 & 80.40 & 79.74 & 78.55 & 80.16 & 81.04 & 83.00 & 83.32 \\
77 & 78.09 & 77.16 & 75.41 & 77.24 & 78.21 & 80.67 & 80.94 \\
78 & 75.61 & 74.37 & 71.95 & 74.01 & 75.08 & 78.11 & 78.32 \\
79 & 72.95 & 71.35 & 68.17 & 70.46 & 71.63 & 75.31 & 75.44 \\
80 & 70.12 & 68.11 & 64.06 & 66.58 & 67.86 & 72.26 & 72.29 \\
\hline
\end{tabular}


Table 4A

Female Non-Smokers

Base Year 1990, 5 Percent Annual Decrease in Hazad Rates

\begin{tabular}{c|ccccccc}
\hline \hline & \multicolumn{7}{|c}{ Hazard Rates Measured in Percent } \\
Age & 1990 & 1991 & 1992 & 1993 & 1994 & 1995 & 1996 \\
\hline 60 & 0.17 & 0.16 & 0.15 & 0.15 & 0.14 & 0.13 & 0.12 \\
61 & 0.20 & 0.19 & 0.18 & 0.17 & 0.16 & 0.16 & 0.15 \\
62 & 0.24 & 0.23 & 0.22 & 0.21 & 0.20 & 0.19 & 0.18 \\
63 & 0.29 & 0.27 & 0.26 & 0.25 & 0.23 & 0.22 & 0.21 \\
64 & 0.34 & 0.33 & 0.31 & 0.29 & 0.28 & 0.27 & 0.25 \\
65 & 0.41 & 0.39 & 0.37 & 0.35 & 0.33 & 0.32 & 0.30 \\
66 & 0.49 & 0.46 & 0.44 & 0.42 & 0.40 & 0.38 & 0.36 \\
67 & 0.58 & 0.55 & 0.52 & 0.50 & 0.47 & 0.45 & 0.43 \\
68 & 0.69 & 0.66 & 0.63 & 0.59 & 0.56 & 0.54 & 0.51 \\
69 & 0.83 & 0.79 & 0.75 & 0.71 & 0.67 & 0.64 & 0.61 \\
70 & 0.99 & 0.94 & 0.89 & 0.85 & 0.80 & 0.76 & 0.72 \\
71 & 1.18 & 1.12 & 1.06 & 1.01 & 0.96 & 0.91 & 0.86 \\
72 & 1.40 & 1.33 & 1.27 & 1.20 & 1.14 & 1.08 & 1.03 \\
73 & 1.67 & 1.59 & 1.51 & 1.43 & 1.36 & 1.29 & 1.23 \\
74 & 1.99 & 1.89 & 1.80 & 1.71 & 1.62 & 1.54 & 1.47 \\
75 & 2.38 & 2.26 & 2.15 & 2.04 & 1.94 & 1.84 & 1.75 \\
76 & 2.84 & 2.69 & 2.56 & 2.43 & 2.31 & 2.19 & 2.08 \\
77 & 3.38 & 3.21 & 3.05 & 2.90 & 2.75 & 2.62 & 2.49 \\
78 & 4.03 & 3.83 & 3.64 & 3.46 & 3.28 & 3.12 & 2.96 \\
79 & 4.81 & 4.57 & 4.34 & 4.12 & 3.92 & 3.72 & 3.53 \\
80 & 5.73 & 5.45 & 5.18 & 4.92 & 4.67 & 4.44 & 4.22 \\
\hline
\end{tabular}

\begin{tabular}{c|ccccccc}
\hline \hline & \multicolumn{7}{|c}{ Conditional Survival Measured in Percent } \\
Age & 1990 & 1991 & 1992 & 1993 & 1994 & 1995 & 1996 \\
\hline 60 & 100.00 & 100.00 & 100.00 & 100.00 & 100.00 & 100.00 & 100.00 \\
61 & 99.82 & 99.82 & 99.83 & 99.84 & 99.85 & 99.86 & 99.86 \\
62 & 99.59 & 99.62 & 99.63 & 99.65 & 99.67 & 99.69 & 99.70 \\
63 & 99.33 & 99.37 & 99.40 & 99.43 & 99.46 & 99.48 & 99.51 \\
64 & 99.02 & 99.07 & 99.12 & 99.16 & 99.20 & 99.24 & 99.28 \\
65 & 98.65 & 98.72 & 98.78 & 98.84 & 98.90 & 98.95 & 99.01 \\
66 & 98.21 & 98.30 & 98.38 & 98.46 & 98.54 & 98.61 & 98.68 \\
67 & 97.69 & 97.80 & 97.91 & 98.01 & 98.11 & 98.21 & 98.30 \\
68 & 97.07 & 97.21 & 97.35 & 97.48 & 97.61 & 97.72 & 97.84 \\
69 & 96.34 & 96.52 & 96.69 & 96.85 & 97.01 & 97.15 & 97.29 \\
70 & 95.47 & 95.69 & 95.90 & 96.10 & 96.29 & 96.48 & 96.65 \\
71 & 94.45 & 94.72 & 94.97 & 95.22 & 95.45 & 95.67 & 95.89 \\
72 & 93.24 & 93.57 & 93.88 & 94.17 & 94.46 & 94.73 & 94.98 \\
73 & 91.82 & 92.21 & 92.59 & 92.95 & 93.29 & 93.61 & 93.92 \\
74 & 90.16 & 90.63 & 91.07 & 91.50 & 91.91 & 92.30 & 92.67 \\
75 & 88.21 & 88.77 & 89.30 & 89.81 & 90.29 & 90.75 & 91.19 \\
76 & 85.95 & 86.60 & 87.23 & 87.83 & 88.40 & 88.94 & 89.47 \\
77 & 83.33 & 84.09 & 84.82 & 85.52 & 86.19 & 86.84 & 87.45 \\
78 & 80.30 & 81.19 & 82.04 & 82.85 & 83.64 & 84.39 & 85.11 \\
79 & 76.84 & 77.86 & 78.84 & 79.78 & 80.69 & 81.56 & 82.39 \\
80 & 72.90 & 74.06 & 75.18 & 76.26 & 77.30 & 78.31 & 79.27 \\
\hline
\end{tabular}


Table 4B

Male Non-Smokers

Base Year 1990, 5 Percent Annual Decrease in Hazad Rates

\begin{tabular}{c|ccccccc}
\hline \hline & \multicolumn{7}{|c}{ Hazard Rates Measured in Percent } \\
Age & 1990 & 1991 & 1992 & 1993 & 1994 & 1995 & 1996 \\
\hline 60 & 0.54 & 0.51 & 0.49 & 0.46 & 0.44 & 0.42 & 0.40 \\
61 & 0.60 & 0.57 & 0.54 & 0.51 & 0.49 & 0.46 & 0.44 \\
62 & 0.66 & 0.63 & 0.60 & 0.57 & 0.54 & 0.51 & 0.49 \\
63 & 0.73 & 0.70 & 0.66 & 0.63 & 0.60 & 0.57 & 0.54 \\
64 & 0.81 & 0.77 & 0.73 & 0.70 & 0.66 & 0.63 & 0.60 \\
65 & 0.90 & 0.86 & 0.81 & 0.77 & 0.73 & 0.70 & 0.66 \\
66 & 1.00 & 0.95 & 0.90 & 0.86 & 0.81 & 0.77 & 0.73 \\
67 & 1.10 & 1.05 & 1.00 & 0.95 & 0.90 & 0.85 & 0.81 \\
68 & 1.22 & 1.16 & 1.10 & 1.05 & 1.00 & 0.95 & 0.90 \\
69 & 1.35 & 1.29 & 1.22 & 1.16 & 1.10 & 1.05 & 1.00 \\
70 & 1.50 & 1.43 & 1.35 & 1.29 & 1.22 & 1.16 & 1.10 \\
71 & 1.66 & 1.58 & 1.50 & 1.42 & 1.35 & 1.29 & 1.22 \\
72 & 1.84 & 1.75 & 1.66 & 1.58 & 1.50 & 1.42 & 1.35 \\
73 & 2.04 & 1.94 & 1.84 & 1.75 & 1.66 & 1.58 & 1.50 \\
74 & 2.26 & 2.14 & 2.04 & 1.94 & 1.84 & 1.75 & 1.66 \\
75 & 2.50 & 2.37 & 2.26 & 2.14 & 2.04 & 1.93 & 1.84 \\
76 & 2.77 & 2.63 & 2.50 & 2.37 & 2.25 & 2.14 & 2.03 \\
77 & 3.07 & 2.91 & 2.77 & 2.63 & 2.50 & 2.37 & 2.25 \\
78 & 3.40 & 3.23 & 3.06 & 2.91 & 2.77 & 2.63 & 2.50 \\
79 & 3.76 & 3.57 & 3.39 & 3.22 & 3.06 & 2.91 & 2.76 \\
80 & 4.16 & 3.96 & 3.76 & 3.57 & 3.39 & 3.22 & 3.06 \\
\hline
\end{tabular}

\begin{tabular}{c|ccccccc}
\hline \hline & \multicolumn{7}{|c}{ Conditional Survival Measured in Percent } \\
Age & 1990 & 1991 & 1992 & 1993 & 1994 & 1995 & 1996 \\
\hline 60 & 100.00 & 100.00 & 100.00 & 100.00 & 100.00 & 100.00 & 100.00 \\
61 & 99.43 & 99.46 & 99.49 & 99.51 & 99.54 & 99.56 & 99.58 \\
62 & 98.81 & 98.87 & 98.92 & 98.98 & 99.03 & 99.08 & 99.12 \\
63 & 98.12 & 98.21 & 98.30 & 98.39 & 98.47 & 98.54 & 98.62 \\
64 & 97.37 & 97.50 & 97.62 & 97.74 & 97.85 & 97.96 & 98.06 \\
65 & 96.54 & 96.71 & 96.87 & 97.02 & 97.17 & 97.31 & 97.44 \\
66 & 95.62 & 95.84 & 96.04 & 96.24 & 96.42 & 96.60 & 96.76 \\
67 & 94.63 & 94.89 & 95.14 & 95.37 & 95.60 & 95.82 & 96.02 \\
68 & 93.53 & 93.84 & 94.14 & 94.43 & 94.70 & 94.96 & 95.20 \\
69 & 92.33 & 92.70 & 93.06 & 93.39 & 93.71 & 94.02 & 94.31 \\
70 & 91.03 & 91.46 & 91.87 & 92.26 & 92.63 & 92.98 & 93.32 \\
71 & 89.60 & 90.09 & 90.57 & 91.02 & 91.44 & 91.85 & 92.25 \\
72 & 88.05 & 88.61 & 89.15 & 89.66 & 90.15 & 90.62 & 91.07 \\
73 & 86.36 & 86.99 & 87.60 & 88.18 & 88.74 & 89.27 & 89.78 \\
74 & 84.52 & 85.24 & 85.92 & 86.58 & 87.20 & 87.80 & 88.37 \\
75 & 82.54 & 83.34 & 84.10 & 84.83 & 85.53 & 86.20 & 86.84 \\
76 & 80.40 & 81.28 & 82.12 & 82.94 & 83.72 & 84.46 & 85.18 \\
77 & 78.09 & 79.06 & 79.99 & 80.89 & 81.75 & 82.58 & 83.37 \\
78 & 75.61 & 76.67 & 77.70 & 78.68 & 79.63 & 80.54 & 81.42 \\
79 & 72.95 & 74.11 & 75.23 & 76.31 & 77.35 & 78.35 & 79.31 \\
80 & 70.12 & 71.38 & 72.59 & 73.76 & 74.89 & 75.98 & 77.03 \\
\hline
\end{tabular}


Figure 1: Life-Expectancy Conditional on Reaching Age 60, 1960-95

\section{Life Expect.: Males at 60 - Years}

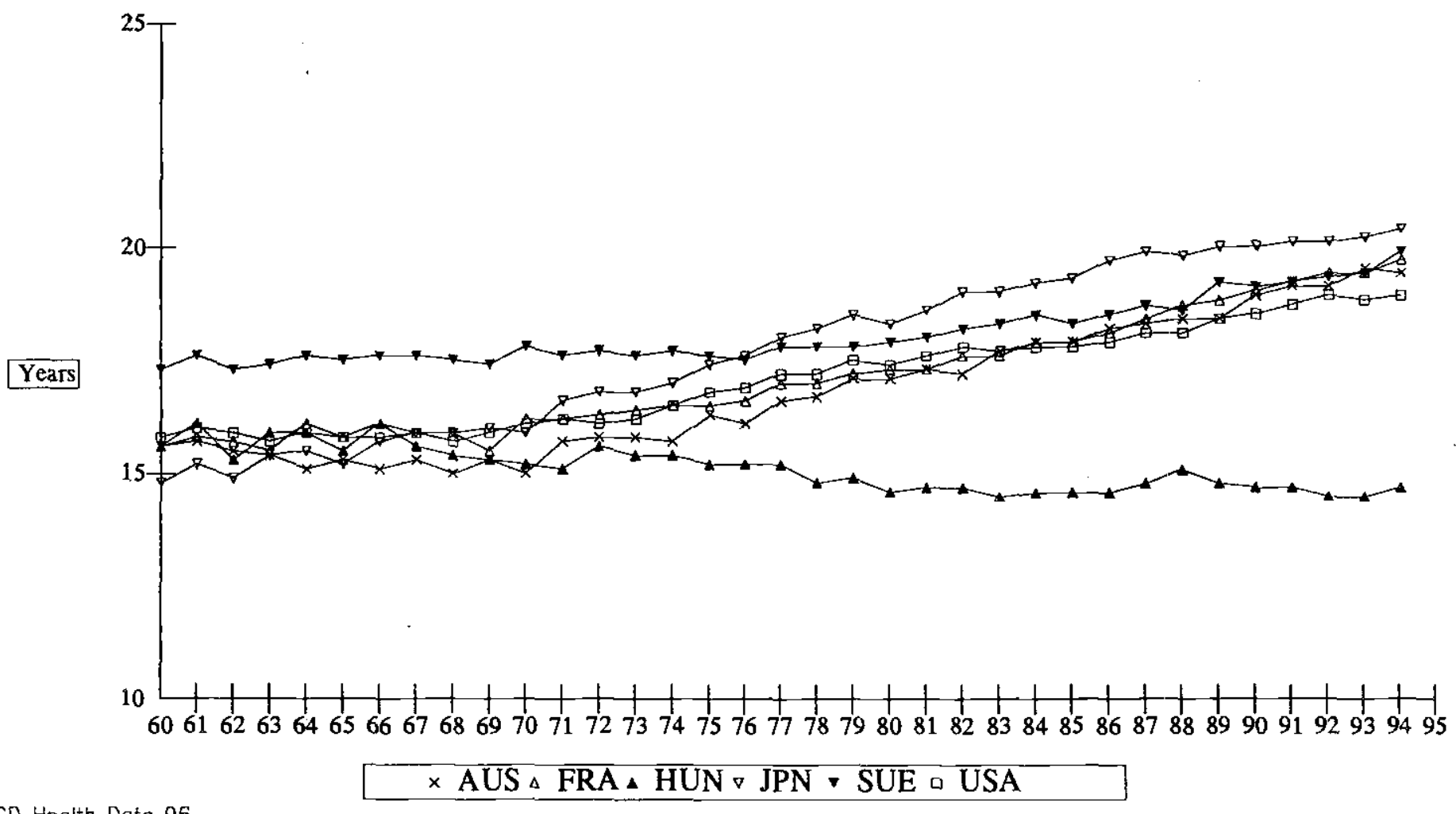

OECD Health Data 96

\section{Life expec.,females at 60 - Years}

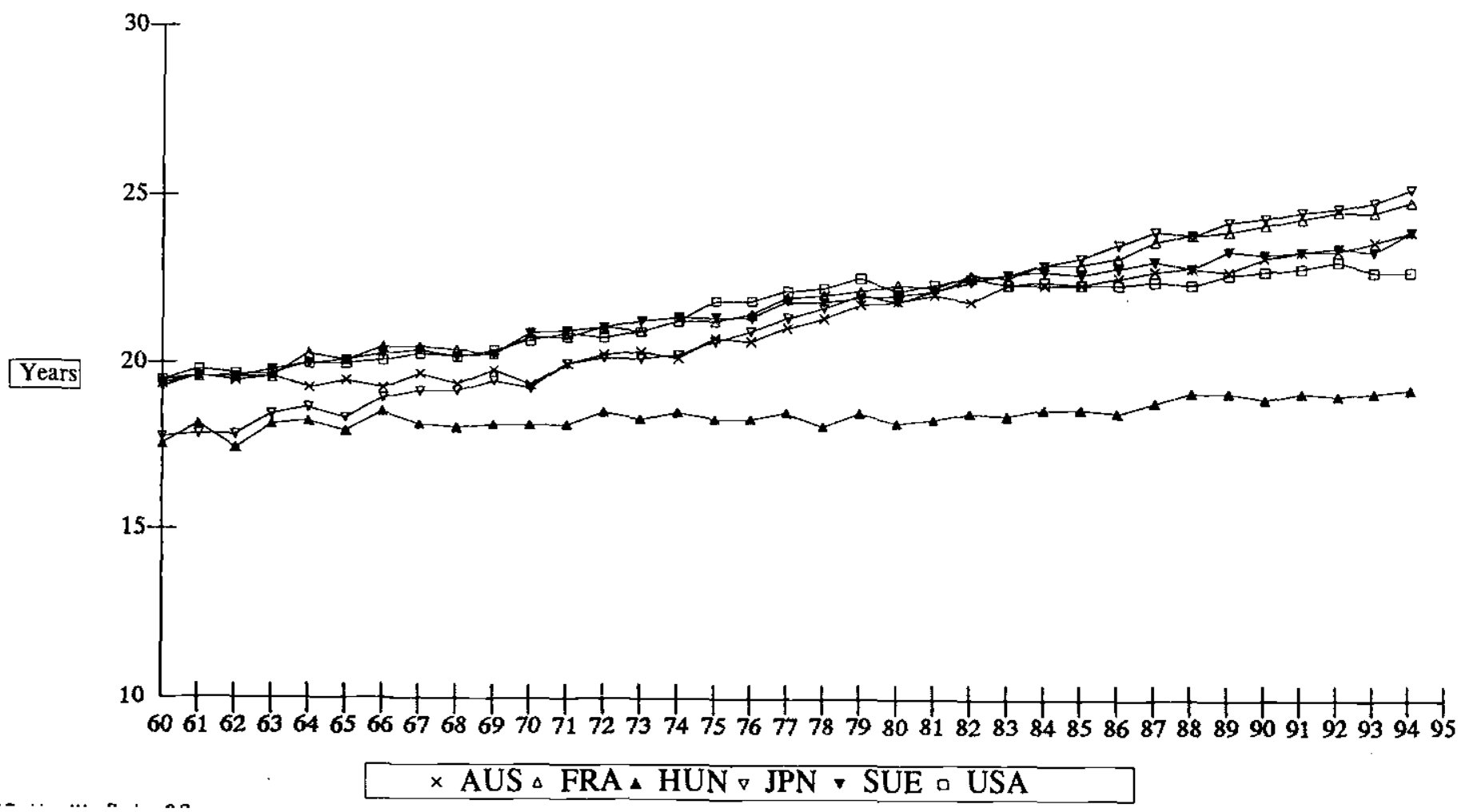




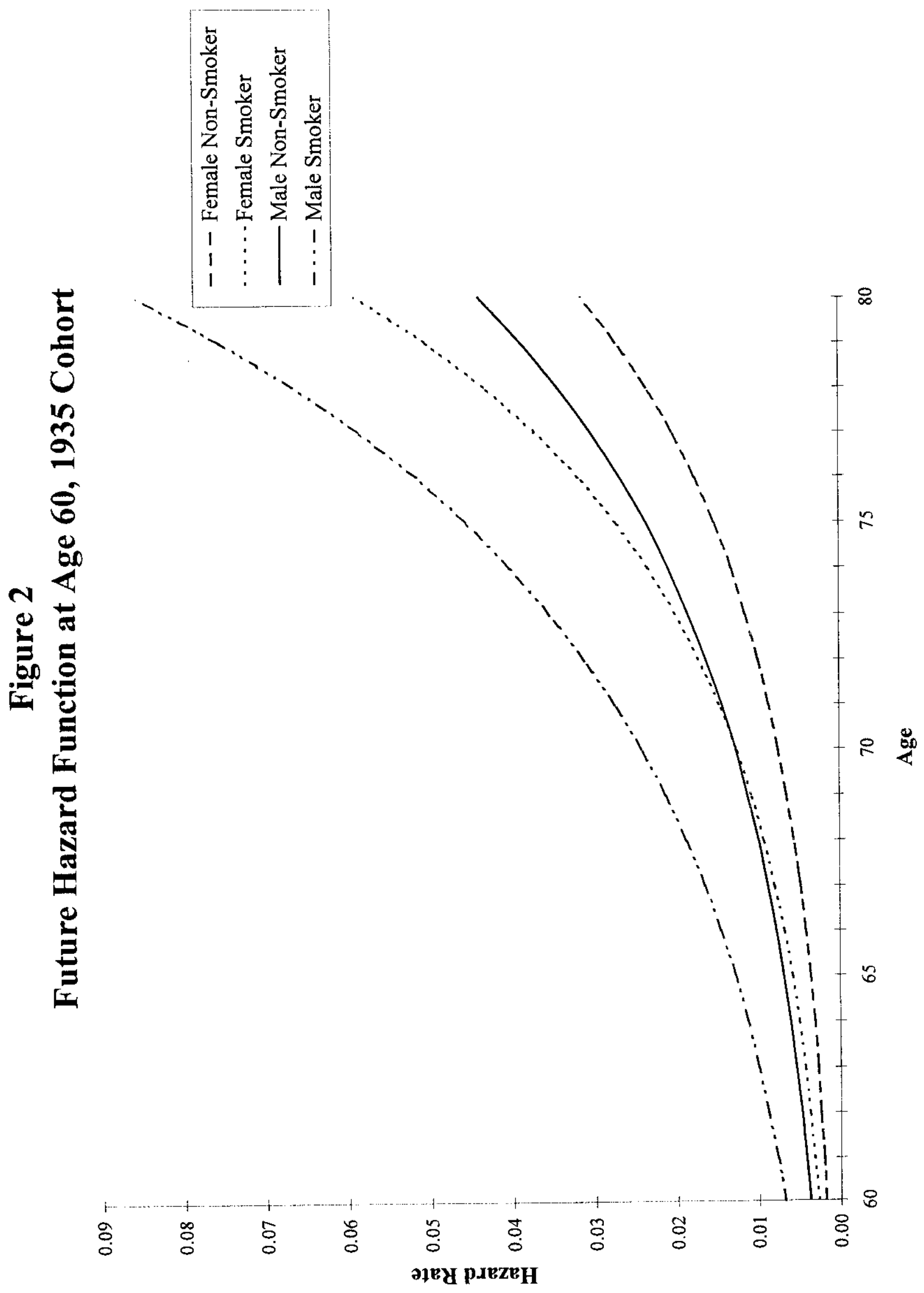




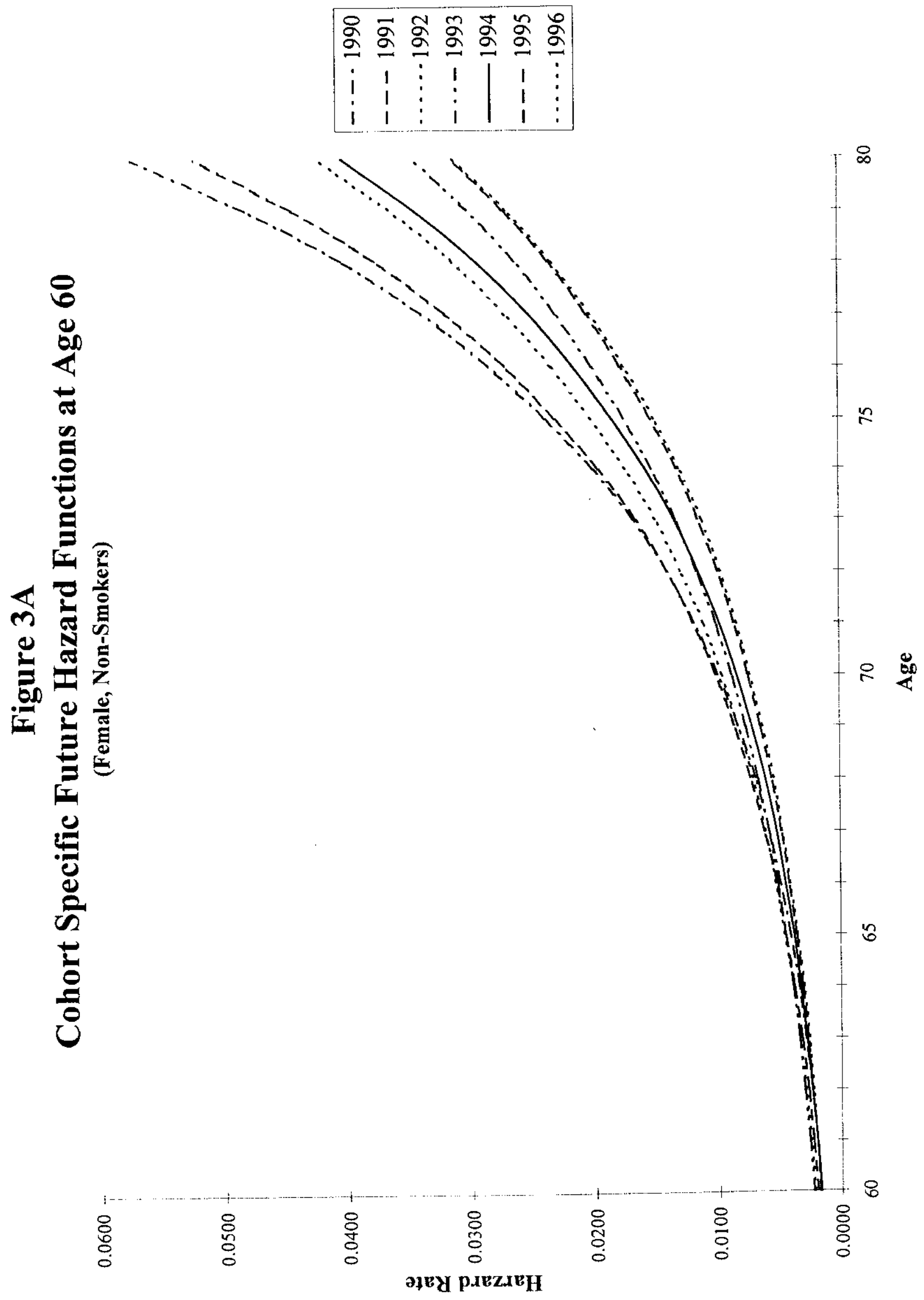




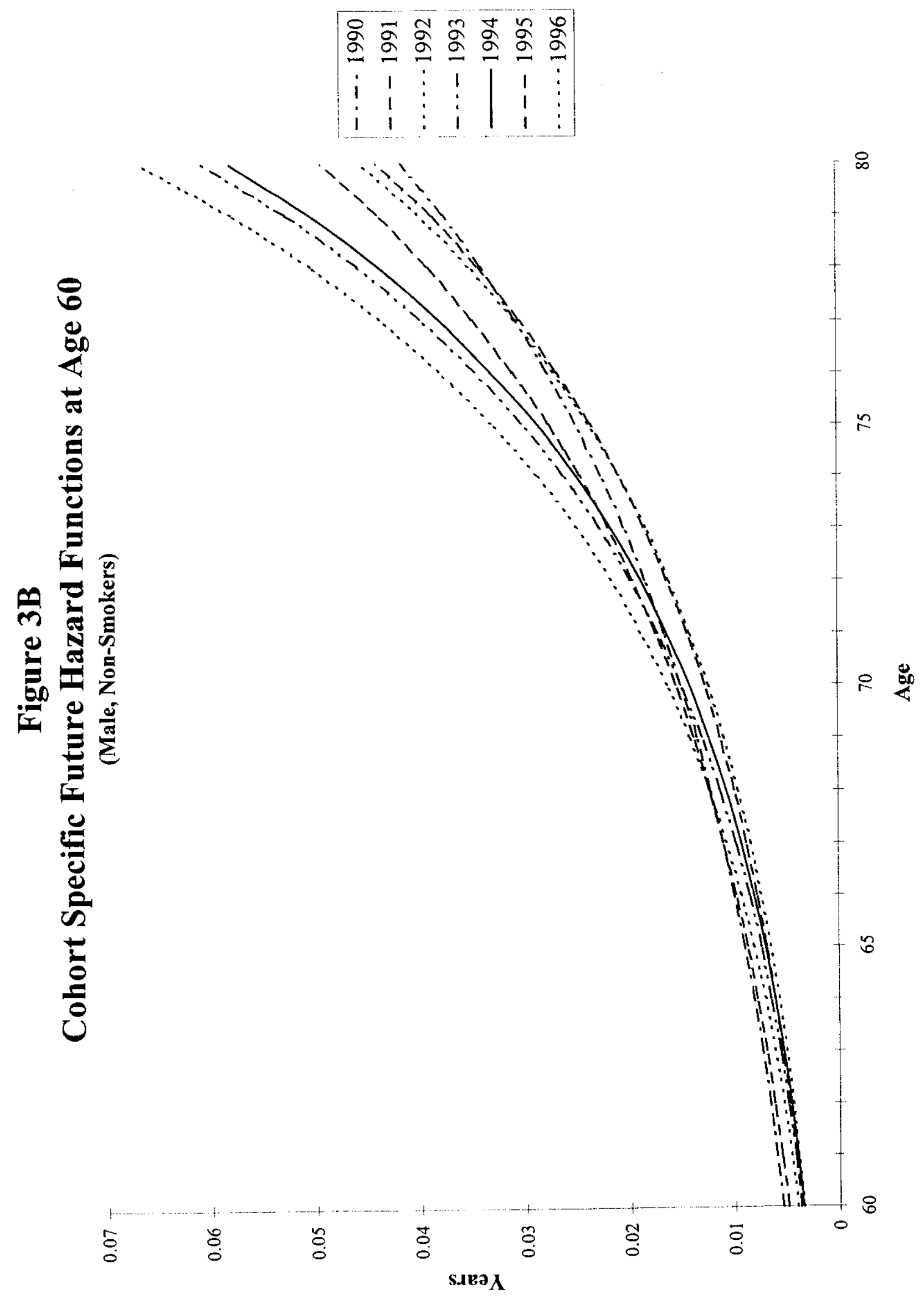




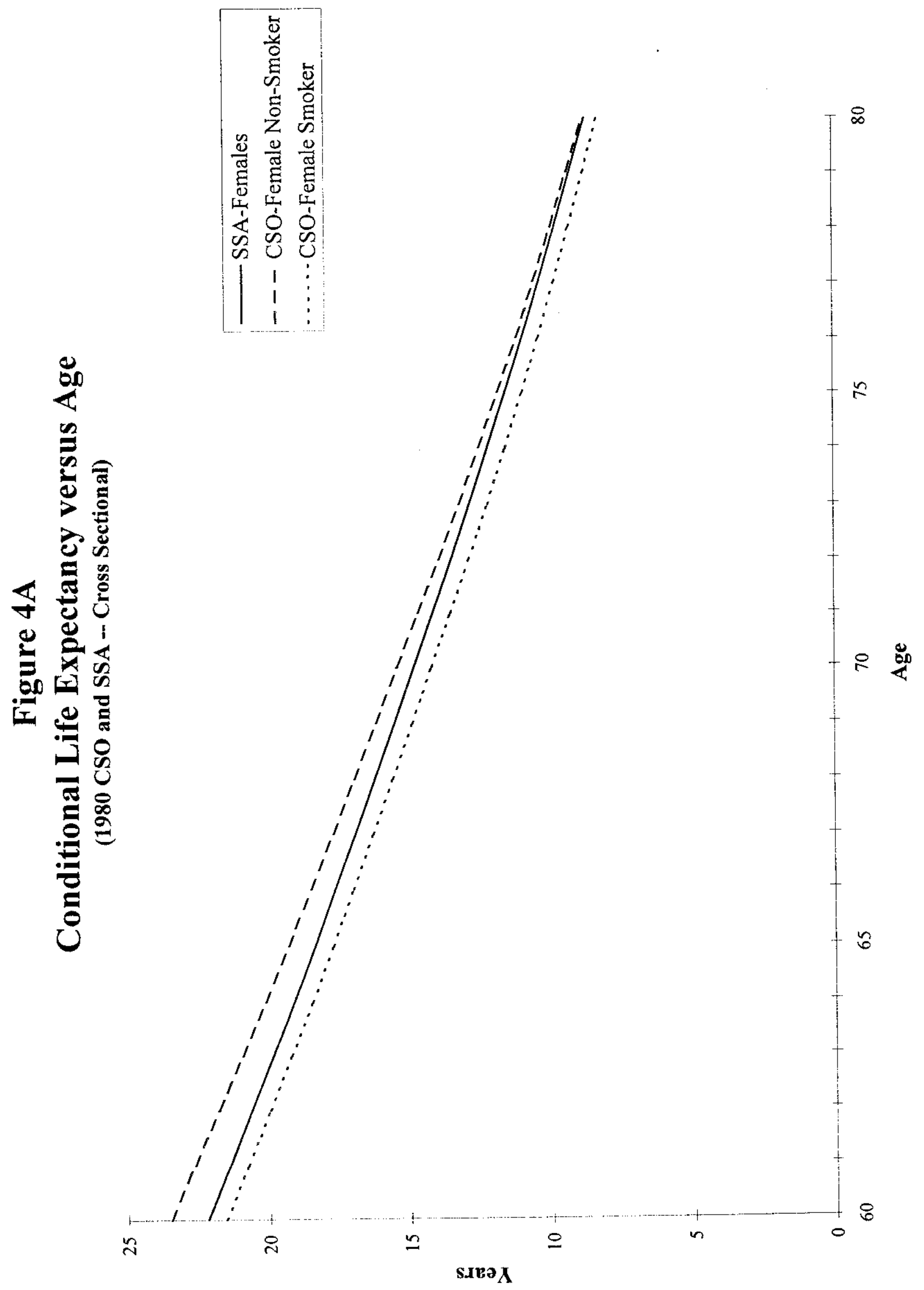




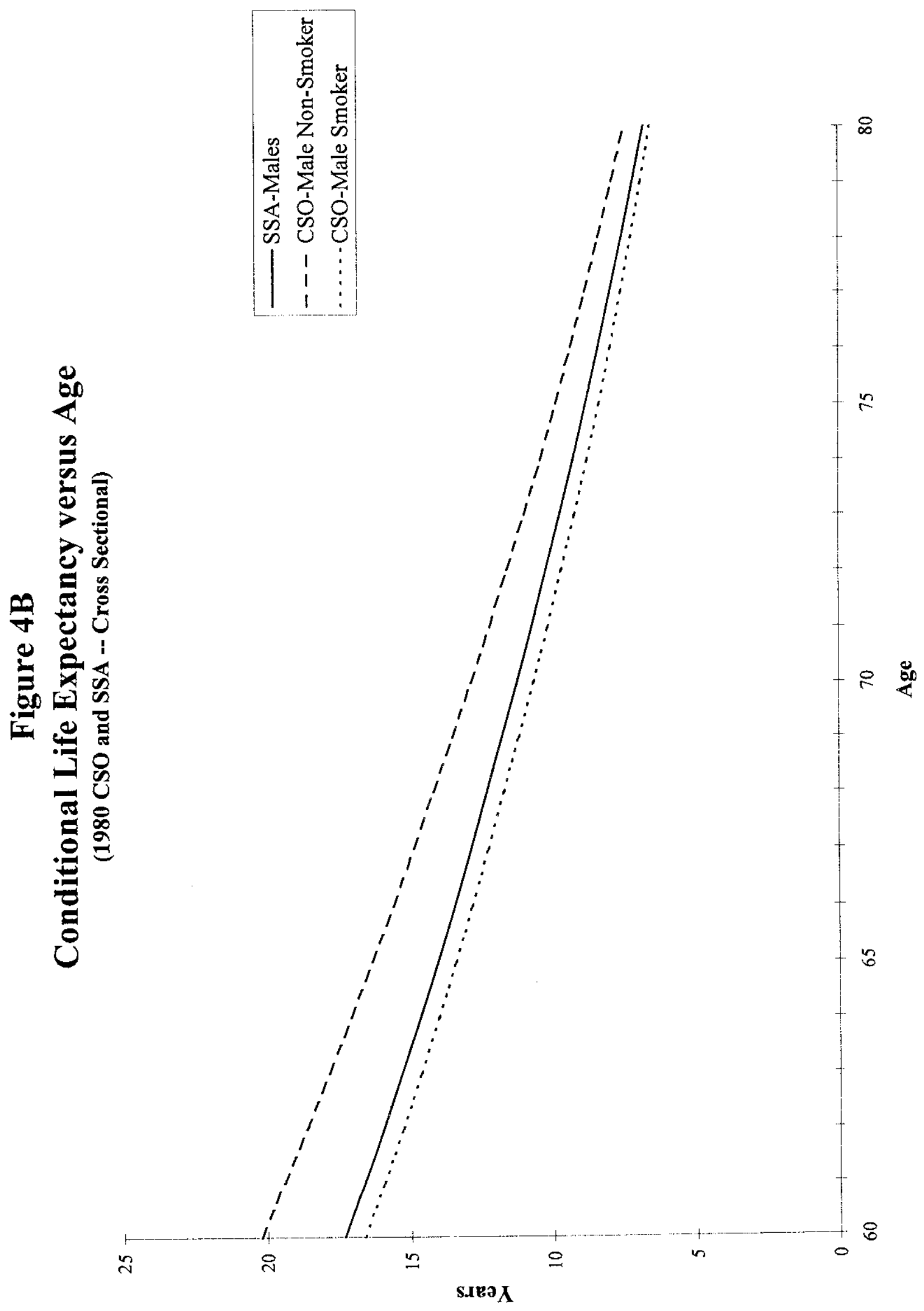

